\title{
Sensitive NMR Approach for Determining the Binding Mode of Tightly Binding Ligand Molecules to Protein Targets
}

\author{
Wan-Na Chen, ${ }^{a}$ Christoph Nitsche, ${ }^{\mathrm{a}, \mathrm{b}}$ Kala Bharath Pilla, ${ }^{\mathrm{a}}$ Bim Graham, ${ }^{\mathrm{c}}$ Thomas Huber, ${ }^{\mathrm{a}}$ Christian D. Klein, ${ }^{\mathrm{b}}$ \\ Gottfried Otting ${ }^{*}$ \\ a Australian National University, Research School of Chemistry, Canberra, ACT 2601, Australia \\ ${ }^{\mathrm{b}}$ Medicinal Chemistry, Institute of Pharmacy and Molecular Biotechnology, Heidelberg University, Im Neuenheimer Feld 364, 69120 \\ Heidelberg, Germany \\ ${ }^{\mathrm{c}}$ Medicinal Chemistry, Monash Institute of Pharmaceutical Sciences, Monash University, Parkville, VIC 3052, Australia
}

\section{Supporting Information Placeholder}

\begin{abstract}
Structure-guided drug design relies on detailed structural knowledge of protein-ligand complexes, but crystallization of co-complexes is not always possible. Here we present a sensitive nuclear magnetic resonance (NMR) approach to determine the binding mode of tightly binding lead compounds in complex with difficult target proteins. In contrast to established NMR methods, it does not depend on rapid exchange between bound and free ligand or on stable isotope labeling, relying instead on a tert-butyl group as a chemical label. Tert-butyl groups are found in numerous protein ligands and deliver an exceptionally narrow and tall ${ }^{1} \mathrm{H}$ NMR signal. We show that a tert-butyl group also produces outstandingly intense intra- and intermolecular NOESY cross-peaks. These enable measurements of pseudocontact shifts generated by lanthanide tags attached to the protein, which in turn allows positioning of the ligand on the protein. Once the ligand has been located, assignments of intermolecular NOEs become possible even without prior resonance assignments of protein side chains. The approach is demonstrated with the dengue virus NS2B-NS3 protease in complex with a high-affinity ligand containing a tert-butyl group.
\end{abstract}

\section{Introduction}

Structure-guided ligand design is a powerful approach in drug discovery. Usually, the approach relies on X-ray crystallography to obtain the 3D structural information of the protein-ligand complexes required to guide further ligand development. NMR spectroscopy is often used to aid this process when single crystals of the protein-ligand complexes cannot be obtained. As the NMR resonances of ligand molecules are often difficult to discriminate against the background of protein NMR signals, however, NMR spectroscopic methods tend to perform best for weakly binding and rapidly exchanging ligands that can be used in large excess over the protein. ${ }^{1}$ In the case of tightly binding ligands, the ligand molecule can, for all intent and purpose, be considered to act like an integral part of the protein.

The most common NMR approaches to characterize the complexes between proteins and tightly binding ligands involve chemical shift perturbations ${ }^{2}$ and nuclear Overhauser effects (NOE). ${ }^{3}$ Both methods rely on the assignment of a large number of NMR signals. In particular, reliable assignments of intermolecular NOESY cross-peaks require either near-complete resonance assignments of the target protein, which are difficult to obtain for large target proteins irrespective of the availability of ${ }^{15} \mathrm{~N}$ or ${ }^{13} \mathrm{C}$-labeled protein samples, or information from independent data, such as site-directed mutagenesis experiments. ${ }^{4}$ Detailed structural interpretation of chemical shift perturbations is difficult and requires measurements with a series of ligand derivatives.

In recent years, paramagnetic NMR methods have increasingly been recruited for structural analysis of protein-ligand complexes, in particular by making use of paramagnetic relaxation enhancements (PRE) and pseudocontact shifts (PCS) generated by site-specifically attached tags. ${ }^{5}$ While much work has focused on these parameters for the analysis of weakly binding complexes, ${ }^{6-13}$ the ligand PCSs are exceedingly small if a large excess of ligand is used. The reverse experiment, generating PCSs in the target protein by attaching a paramagnetic metal complex to the ligand, requires a significant chemical modification of the ligand and comprehensive resonance assignments of the protein for data interpretation. ${ }^{14,15}$ Examples are rare where PCSs have been used to establish the structure and orientation of a tightly binding ligand at its binding site on the protein. ${ }^{6,11,16,17}$ The fundamental problem in these cases arises from the difficulty in identifying the resonances of the tightly bound ligand. In the 
special situation of a protein-protein complex, isotope labeling allows selective observation of either protein component, which has been used for structure analysis of high-affinity protein-protein complexes using PCSs induced by paramagnetic lanthanide ions. ${ }^{6,17}$ In the case of a small-molecule ligand, however, synthesis of an isotope-labeled version would usually be prohibitively laborious. An alternative strategy employs selective suppression of the ${ }^{1} \mathrm{H}$ NMR spectrum of the protein by isotope labeling, either using ${ }^{15} \mathrm{~N} /{ }^{13} \mathrm{C}$ labeling in combination with half-filter pulse sequences, ${ }^{18}$ or by perdeuteration of the protein. ${ }^{19}$ Either approach is imperfect, as the half-filters achieve only incomplete suppression of the protein NMR signals, due to non-uniform one-bond coupling constants, and are associated with significant signal decay by relaxation, while very high deuteration levels are required to reduce the residual protein ${ }^{1} \mathrm{H}$ NMR signals to a level below those of the ligand. Instead of relying on costly isotope labeling, the present approach makes use of the unique NMR properties of tert-butyl groups.

The ${ }^{1} \mathrm{H}$ NMR signal of a tert-butyl group is an intense singlet with a chemical shift in the range of about 1.0 to $1.5 \mathrm{ppm}$ depending on the chemical environment. Owing to rapid methyl rotation and methyl reorientation within this flexible group, the signal of a solvent-exposed tert-butyl group is much narrower than protein ${ }^{1} \mathrm{H}$ NMR signals, enabling its detection even in protein complexes of high molecular mass without any isotope labeling. ${ }^{20}$ In experiments aimed at probing chemical exchange phenomena, we observed that the tert-butyl group also produces NOESY cross-peaks that are much more intense than anticipated and can be observed even under conditions where cross-peaks of the protein are barely detectable. This opens a new route to characterize the binding mode of a ligand labeled with a tert-butyl group. First, the NOESY cross-peaks with the tert-butyl enable measurements of PCSs induced by paramagnetic tags attached to the protein at different sites. These data position the tert-butyl group with respect to the protein. If intraligand NOEs with the tert-butyl group can be observed, the PCSs of additional ligand protons can be used to orient the ligand in its binding site. Finally, intermolecular NOEs with the tert-butyl group further pinpoint its location on the protein.

We demonstrate the approach with the structure determination of the complex between the two-component dengue virus NS2B-NS3 protease (NS2B-NS3pro) from serotype 2 (in the following referred to as DENpro) and a newly developed ligand that contains a boronic acid warhead, binds with high affinity, and contains a tert-butyl group (C. Nitsche and C. D. Klein, manuscript in preparation). Although a dengue vaccine has been developed that is effective against all serotypes, the vaccine offers only incomplete protection and is ineffective in children below the age of 6 , who need it most. ${ }^{21}$ Dengue causes severe complications and is spreading rapidly, ${ }^{22}$ making DENpro a drug target of high priority. ${ }^{23-25}$
Despite intense efforts over many years, however, crystallization of DENpro remains difficult and only a single structure has been published, which proved to be of an inactive conformation (PDB code 2FOM) ${ }^{26}$ Co-crystal structures with inhibitors are available of serotype 3 (PDB code $3 \mathrm{U} 1 \mathrm{I}$ and $3 \mathrm{U} 1 \mathrm{~J})^{27}$ and of the homologous West Nile virus protease, ${ }^{26}$ which allow modeling of the structure of DENpro. In the absence of exact structural information, the development of high-affinity inhibitors has been slow. An effective inhibition constant of $43 \mathrm{nM}$ was reported for the peptidic inhibitor BzNle-Lys-Arg-Arg-B $(\mathrm{OH})_{2}$ owing to the presence of the electrophilic boronic acid warhead which is thought to form a covalent bond to Ser135 at the active site of DENpro. ${ }^{28} \mathrm{~A}$ range of further inhibitors lacking a boronic acid warhead has been developed, ${ }^{25,29,30}$ but their binding modes remain uncertain in the absence of experimental confirmation for any of the computational models built.

DENpro has a molecular mass of about $27 \mathrm{kDa}$ and degrades readily in the absence of high-affinity ligands. Its NMR spectrum shows broad resonances and strong signal overlap, and varies between different constructs and inhibitors. ${ }^{31-35}$ The well-resolved ${ }^{15} \mathrm{~N}-\mathrm{HSQC}$ cross-peaks comprise about half of the backbone amides. We identified three single-cysteine mutants of DENpro for the attachment of paramagnetic lanthanide tags, which generate pronounced PCSs in the NMR spectrum of the protein. ${ }^{31}$ Using the resolved ${ }^{15} \mathrm{~N}-\mathrm{HSQC}$ cross-peaks, PCS measurements are straightforward and allowed characterization of the conformation of DENpro in isolation and in complex with a small-molecule and a protein inhibitor, respectively. ${ }^{20,31}$ Assessing the binding mode of the synthetic non-protein inhibitor, however, proved intractable because of the difficulty in observing and assigning intermolecular NOEs.

In the following we report the binding mode of the highaffinity ligand $\mathbf{1}$ (Figure 1) to DENpro. This is the first time that the complex between DENpro and a small-molecule ligand has been modeled at atomic resolution using experimental NMR data. Importantly, the new protocol succeeded with a limited set of ${ }^{15} \mathrm{~N}-\mathrm{HSQC}$ cross-peaks of backbone amides, which are sufficiently well resolved to enable a straightforward transfer of their assignments between the free protein and complexes with different inhibitors.

\section{Materials and Methods}

Sample preparation. Three single-cysteine mutants of DENpro were prepared. The mutants were Ala57 $7^{*} \mathrm{Cys}$ (site A; the asterisk marks residues in NS2B), Ser34Cys (site B), and Ser68Cys (site C). Uniformly ${ }^{15} \mathrm{~N}$-labeled protein samples were produced by over-expression in E. coli and selectively isotope-labeled samples by cell-free synthesis as described previously. ${ }^{31}$ The samples were ligated with $\mathrm{C} 2-\mathrm{Ln}^{3+}$ tags (Figure S1) as described, ${ }^{31,35,36}$ where $\mathrm{Ln}^{3+}$ is either $\mathrm{Y}^{3+}$, $\mathrm{Tm}^{3+}$, or $\mathrm{Tb}^{3+}$. 
Ligands $\mathbf{1}$ and $\mathbf{2}$ were synthesized as described elsewhere (C. Nitsche and C. D. Klein, manuscript in preparation).

NMR measurements. All NMR spectra were measured on a Bruker $800 \mathrm{MHz}$ NMR spectrometer equipped with a $5 \mathrm{~mm}$ TCI cryoprobe, using $3 \mathrm{~mm}$ NMR tubes. ${ }^{15} \mathrm{~N}-\mathrm{HSQC}$ spectra were recorded with $t_{1 \max }=262 \mathrm{~ms}$ and $t_{2 \max }=160 \mathrm{~ms}$. NOESY spectra were recorded with a mixing time of $200 \mathrm{~ms}$, $t_{1 \max }=58 \mathrm{~ms}$, and $t_{2 \max }=232 \mathrm{~ms}$. The total recording times of the NOESY spectra varied from $4 \mathrm{~h}$ for diamagnetic samples to $8 \mathrm{~h}$ for paramagnetic samples.

PCSs were measured as ${ }^{1} \mathrm{H}$ chemical shifts observed for DENpro tagged with $\mathrm{C} 2-\mathrm{Tm}^{3+}$ or $\mathrm{C} 2-\mathrm{Tb}^{3+}$ tags minus the corresponding chemical shifts measured with DENpro tagged with diamagnetic $\mathrm{C} 2-\mathrm{Y}^{3+}$. PCSs are through-space effects that follow the equation ${ }^{37}$

$\Delta \delta^{\mathrm{PCS}}=1 /\left(12 \pi r^{3}\right)\left[\Delta \chi_{\mathrm{ax}}\left(3 \cos ^{2} \theta-1\right)+1.5 \Delta \chi_{\mathrm{rh}} \sin ^{2} \theta \cos 2 \varphi\right]$

where $\Delta \delta^{\mathrm{PCS}}$ is the PCS measured in ppm, $r$ is the distance of the nuclear spin from the metal ion, $\Delta \chi_{a x}$ and $\Delta \chi_{\mathrm{rh}}$ are the axial and rhombic components of the magnetic susceptibility anisotropy tensor $\Delta \chi$, and $\theta$ and $\varphi$ are the polar angles describing the position of the nuclear spin with respect to the principal axes of the $\Delta \chi$ tensor. We used the PCSs of backbone amide protons (Table S1) to fit the $\Delta \chi$ tensors to the coordinates of DENpro models generated by Rosetta. ${ }^{38}$

PREs of the tert-butyl resonance were measured by comparing its ${ }^{1} \mathrm{H}$ NMR line widths in resolved NOESY cross-peaks recorded for samples tagged with paramagnetic and diamagnetic tags.

Modeling of the protein-ligand complex. A structural model of DENpro in the catalytically active conformation was obtained using the program Modeller ${ }^{39}$ and the crystal structure $3 \mathrm{U}^{2} \mathrm{I}^{27}$ of the protease from serotype 3 as the template. A total of 100 models were generated following the advanced modeling protocol, ${ }^{40}$ and the best model was selected based on the Discrete Optimized Potential Energy (DOPE) score. ${ }^{41}$

The program AutoDock-Vina ${ }^{42}$ was used to generate 20 different poses of the docked ligand. Each pose was checked for agreement with the ligand PCSs using six different $\Delta \chi$ tensors, which had been determined from the PCSs of the backbone amides of DENpro with $\mathrm{C} 2-\mathrm{Tm}^{3+}$ and $\mathrm{C} 2-\mathrm{Tb}^{3+}$ tags at three sites. The best-fitting pose was selected for further refinement by the software suite Rosetta ${ }^{43}$ to model a covalent bond between the boron and the side chain oxygen of Ser135. Further restraints were introduced to ensure tetrahedral coordination of the boron, as detected in boronic acid complexes of other serine proteases such as the hepatitis $\mathrm{C}$ virus protease, ${ }^{44}$ and planarity of the guanidinum groups. The all-atom Relax module of Rosetta ${ }^{43}$ was used to refine the amino acid side chain conformations in the substrate binding site, following the protocol available in the protocol demonstrations (demos directory) of the Rosetta software suite. ${ }^{45}$ From the models generated by the all-atom Relax module, the model that best fulfilled the backbone PCSs of DENpro was selected as the final structure. New $\Delta \chi$ tensors were fitted to each model to find the structure with the lowest PCS score. ${ }^{46}$

\section{Results}

${ }^{1} \mathrm{H}$ NMR resonance of the tert-butyl group of ligand 1 in the absence and presence of DENpro. In the DENpro construct used in the present work, the linker between NS2B and NS3 contained the natural recognition site EVKKQR, leading to autoproteolytic cleavage at this site. We have shown previously that the resulting product assumes the enzymatically active closed conformation of the protease. ${ }^{35}$ The unlinked construct degraded during NMR measurements in less than a day, but was stable for months in the presence of ligand $\mathbf{1}$.

The 1D ${ }^{1} \mathrm{H}$ NMR spectrum of the free ligand shows four prominent resonances for the aromatic rings between 7 and $8 \mathrm{ppm}$, and a particularly intense NMR signal for the tertbutyl group (Figure 1). The signal of the tert-butyl group is also easily discernable in the 1:1 complex with DENpro, whereas the aromatic resonances of the ligand are difficult to identify even in a sample prepared with a high level of perdeuteration of aromatic residues (Tyr, Phe, and Trp). The chemical shift of the tert-butyl group of ligand $\mathbf{1}$ in the bound state is slightly downfield compared with the chemical shift in the free state. In the presence of excess ligand, the signals of bound and free ligand were observed simultaneously, indicating that any chemical exchange is slow as expected for a tightly bound ligand (data not shown).

PCS measurements. The strategy of the present work relies on PCS measurements of the protein (to determine the $\Delta \chi$ tensors) and of the ligand (to determine the position of the ligand relative to the $\Delta \chi$ tensors and thus relative to the protein). To account for possible conformational changes caused by ligand binding, PCSs of DENpro were measured in ${ }^{15} \mathrm{~N}$-HSQC spectra recorded of the complex between ${ }^{15} \mathrm{~N}$ labeled DENpro and ligand $\mathbf{1}$, using $\mathrm{C} 2-\mathrm{Tm}^{3+}$ and $\mathrm{C} 2-\mathrm{Tb}^{3+}$ tags at sites $\mathrm{A}-\mathrm{C}$, with $\mathrm{C} 2-\mathrm{Y}^{3+}$ tagged samples as diamagnetic reference (Figures S2-S4). The PCSs were very similar, but not identical, to PCSs measured previously for samples without inhibitor ${ }^{35}$ and with the protein inhibitor BPTI. ${ }^{17} \mathrm{~A}$ total of 222 PCSs (Table S1) were measured and used to determine the $\Delta \chi$-tensor parameters (Table S3).

PCSs of the bound ligand $\mathbf{1}$ sometimes proved difficult to determine from simple $1 \mathrm{D}{ }^{1} \mathrm{H}$ NMR spectra. The intense ${ }^{1} \mathrm{H}$ NMR resonance of the tert-butyl group was readily detected in the diamagnetic samples, but PREs combined with changes in the NMR spectrum of the protein can make it difficult 
difficult to identify the resonance in the paramagnetically tagged samples (Figure S5).
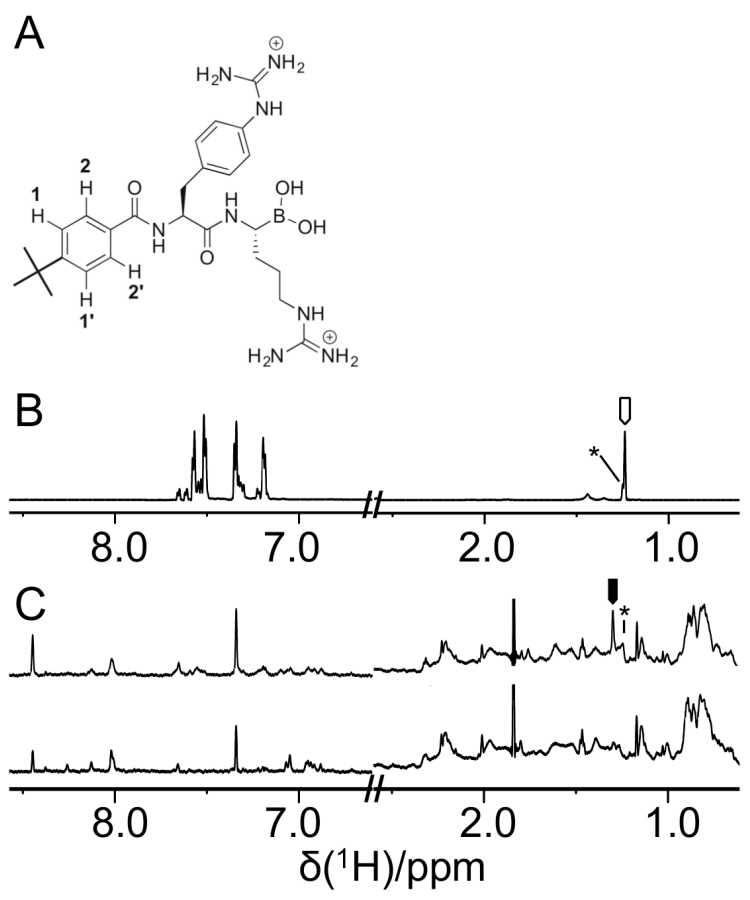

Figure 1. 1D ${ }^{1} \mathrm{H}$ NMR spectra of ligand $\mathbf{1}$ without and with DENpro. (A) Chemical structure of ligand $\mathbf{1}$. Ligand $\mathbf{2}$ is structurally identical except for the absence of the tert-butyl group. (B) $1 \mathrm{D}{ }^{1} \mathrm{H}$ NMR spectrum of ligand $\mathbf{1}$ in the absence of DENpro. The spectrum was recorded at $25{ }^{\circ} \mathrm{C}$ in NMR buffer $(20$ mM MES, pH 6.5, $50 \mathrm{mM} \mathrm{NaCl}$ ) using a $800 \mathrm{MHz}$ NMR spectrometer. The downfield region of the spectrum was scaled up 8 -fold relative to the upfield part of the spectrum. The open arrow marks the ${ }^{1} \mathrm{H}$ NMR resonance of the tert-butyl group. The star identifies the signal from an impurity. (C) $1 \mathrm{D}^{1} \mathrm{H}$ NMR spectra of $50 \mu \mathrm{M}$ solutions of DENpro in deuterated NMR buffer without ligand (bottom trace) and in a 1:1 complex with ligand 1 (top trace). The spectral appearance of the aromatic region was simplified by perdeuteration of Tyr, Phe, and Trp. Signals at 7.3 and $8.0 \mathrm{ppm}$ are from the C-terminal His $_{6}$-tag. The low-field region was scaled up 2-fold relative to the highfield region. The resonance of the tert-butyl group of ligand $\mathbf{1}$ is marked by a filled arrow. The star identifies the signal of a nonbinding impurity.

In contrast, NOESY spectra turned out to yield intense cross-peaks with the tert-butyl resonance that could easily be followed even when the tert-butyl resonance was broadened by PRE. In addition, the NOESY spectra yield PCSs not only for the tert-butyl resonance itself but also for the protons involved in the NOEs with the tert-butyl group. Figure $2 \mathrm{~B}$ illustrates the intensity of the tert-butyl cross-peaks with the wild-type protein. The cross-peaks are readily identified by their narrow lineshape in the detection dimension. As expected, they were absent from the corresponding NOESY spectrum recorded with ligand $\mathbf{2}$, which is the same as ligand
1 but without the tert-butyl group (Figure 2A). Particularly intense cross-peaks are observed with protons at about 7.5 ppm, which were assigned to the aromatic ligand protons in the positions ortho and meta to the tert-butyl group labeled 1, 1', 2, and 2' in Figure 1A. (Using a sample prepared with ${ }^{15} \mathrm{~N}$ labeled DENpro, a NOESY spectrum recorded without ${ }^{15} \mathrm{~N}$ decoupling confirmed that these NOEs are not with amide protons.) Additional cross-peaks at about 0.7 and $1.7 \mathrm{ppm}$ cannot be explained as intra-ligand NOEs and, based on the chemical shifts, include NOEs with methyl groups.

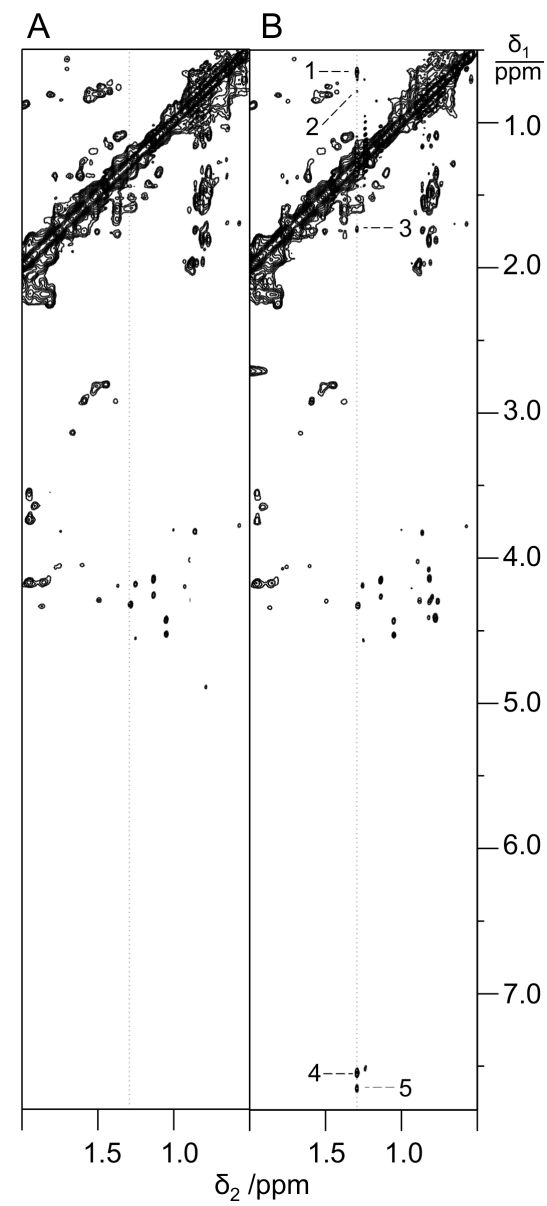

Figure 2. NOESY spectra of DENpro in complex with ligands 1 and 2 . The spectra were recorded at $25{ }^{\circ} \mathrm{C}$ of $150 \mu \mathrm{M}$ solutions of unlabeled wild-type DENpro in NMR buffer containing $10 \%$ $\mathrm{D}_{2} \mathrm{O}$, using $3 \mathrm{~mm}$ NMR tubes in a $5 \mathrm{~mm}$ TCI cryoprobe. Experimental parameters: $200 \mathrm{~ms}$ mixing time, $t_{1 \max }=58 \mathrm{~ms}, t_{2 \max }=$ $232 \mathrm{~ms}$, total recording time per spectrum $4 \mathrm{~h}$. The spectral region shown captures the NOE cross-peaks of the tert-butyl resonance. (A) NOESY spectrum of the complex with ligand 2. (B) NOESY spectrum of the complex with ligand 1. Five crosspeaks with the tert-butyl resonance are labeled. Note that these cross-peaks were readily detected, while other cross-peaks, e.g. with amide protons, were much weaker or unobservable.

Figure 3 illustrates the measurement of PCSs from the NOESY cross-peaks with the tert-butyl resonance. The crosspeaks were preserved between wild-type DENpro and DEN- 
pro tagged with diamagnetic $\mathrm{C} 2-\mathrm{Y}^{3+}$ tags, and were displaced by PCSs in the samples containing paramagnetic tags. Different to backbone amides, where PCSs displace ${ }^{15} \mathrm{~N}-\mathrm{HSQC}$ cross-peaks along mostly parallel lines owing to the close spatial proximity of ${ }^{1} \mathrm{H}$ and ${ }^{15} \mathrm{~N}$ spins, the PCSs observed for the protons involved in NOEs with the tert-butyl resonance were mostly different from the PCS of the tert-butyl resonance itself, as expected for spins that are located at more disparate positions relative to the $\Delta \chi$ tensors of the paramagnetic tags. Importantly, the $\mathrm{C} 2-\mathrm{Tm}^{3+}$ and $\mathrm{C} 2-\mathrm{Tb}^{3+}$ tags produced PCSs of opposite sign ${ }^{31,36}$ and the NOESY cross-peaks of the three samples tagged with $\mathrm{C} 2-\mathrm{Tm}^{3+}, \mathrm{C} 2-\mathrm{Y}^{3+}$, and $\mathrm{C} 2-$ $\mathrm{Tb}^{3+}$ tags could be connected by almost straight lines. This greatly aids the identification of the paramagnetically shifted cross-peaks, even when the cross-peaks were significantly broadened by PREs, as for the paramagnetic samples tagged at site $\mathrm{B}$ (Figure 3B).

Altogether, the NOESY cross-peaks observed with the tertbutyl resonance delivered 18 ligand PCSs together with 14 protein PCSs (Table S2). The ligand PCSs immediately enable a qualitative structural interpretation regarding the orientation of the tert-butylphenyl group relative to the $\Delta \chi$ tensors. For example, the PCSs obtained with the tags at site B decrease in magnitude in moving from the protons at positions $2 / 2$ ' to those at positions $1 / 1^{\prime}$ to the tert-butyl group (Figure 3B), suggesting that the tert-butyl group faces away from the tag at site $\mathrm{B}$. This conclusion is confirmed by the broad line widths of cross-peaks observed for the $\mathrm{H}-2 / 2$ ' resonances in the paramagnetic samples, particularly for DENpro tagged at site B, which can be attributed to PREs due to proximity to the tag.

PRE measurement. As the tert-butyl resonance is a singlet, PREs can simply be measured as the difference in line width observed in paramagnetic and diamagnetic samples. The NOESY cross-peaks of Figure 3 clearly show that the tertbutyl resonance is broader in the samples with paramagnetic versus diamagnetic tags, and broader with $\mathrm{Tb}^{3+}$ tags than with $\mathrm{Tm}^{3+}$ tags, as expected from the greater paramagnetic moment of $\mathrm{Tb}^{3+} .{ }^{47}$ It is difficult, however, to convert the PREs into quantitative distance restraints from the metal ions. First, the significant anisotropy of the magnetic susceptibility tensors associated with $\mathrm{Tb}^{3+}$ and $\mathrm{Tm}^{3+}$ needs to be taken into account. ${ }^{48}$ Second, the PREs can be compromised by crosscorrelation effects with nuclear chemical shift anisotropies. ${ }^{49}$ Most importantly, however, the linker of the $\mathrm{C} 2$ tag is not entirely rigid, resulting in multiple possible metal positions. For a conservative estimate of the distance restraint indicated by a PRE, we calculated the largest distance compatible with the $\Delta \chi$ tensor anisotropies determined from the PCSs using the anisotropic Curie-spin relaxation equations ${ }^{44}$ with a rotational correlation time of $10 \mathrm{~ns}$. We only used the data from site B, which showed the greatest PRE effects (Figure 3 ). In this construct, the $\mathrm{C} 2-\mathrm{Tb}^{3+}$ and $\mathrm{C} 2-\mathrm{Tm}^{3+}$ tags broadened the tert-butyl signal by 22 and $13 \mathrm{~Hz}$, respectively, rela- tive to the diamagnetic sample with the $\mathrm{C} 2-\mathrm{Y}^{3+}$ tag. Both measurements correspond to a distance from the paramagnetic center of about $15.5 \AA$. To account for the uncertainty in metal position, we converted the PREs observed for mutant $B$ into an upper distance restraint of $20 \AA$.

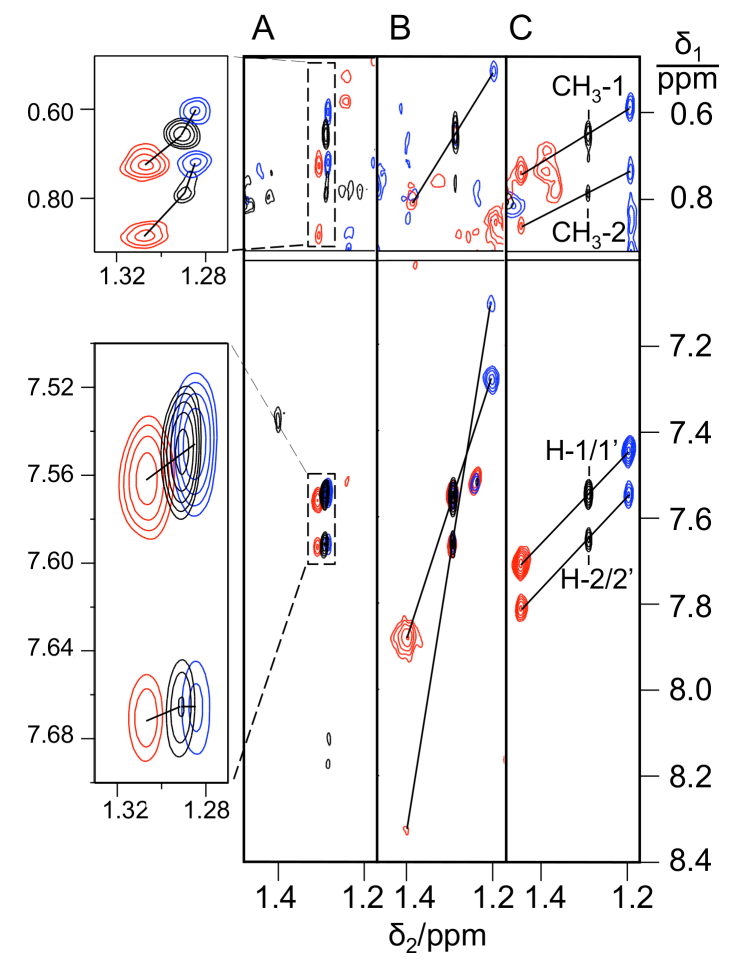

Figure 3. PCSs observed in 2D NOESY spectra of DENpro with $\mathrm{C} 2$ tags at three different sites. The spectra were recorded of $150 \mu \mathrm{M}$ solutions of ${ }^{15} \mathrm{~N}$-labeled DENpro complexes with ligand $\mathbf{1}$ in NMR buffer at $25^{\circ} \mathrm{C}$. The figure shows superimpositions of NOESY spectra for samples tagged with $\mathrm{C}_{2}-\mathrm{Y}^{3+}$ (black), $\mathrm{C} 2-\mathrm{Tm}^{3+}$ (blue) and C2- $\mathrm{Tb}^{3+}$ (red). The spectral regions shown contain cross-peaks between the tert-butyl resonance and protons in the aromatic and methyl regions of the NMR spectrum. PCSs are identified by lines drawn between cross-peaks of the diamagnetic samples and their corresponding peaks in the paramagnetic samples. (A) NOESY spectra of the complex tagged at site A. (B) Same as (A), but for the complex tagged at site B. (C) Same as (A), but for the complex tagged at site C. NOEs with two unassigned methyl groups are labeled as $\mathrm{CH}_{3}-1$ and $\mathrm{CH}_{3}-2$. The NOEs with two aromatic protons were attributed to the protons $1 / 1^{\prime}$ and $2 / 2^{\prime}$ of the ligand (Figure $1 \mathrm{~A}$ ).

PCS-guided modeling of the protein-ligand complex. As no crystal structure of DENpro in the active conformation is available and the amino acid sequences of NS2B-NS3pro of serotypes 2 and 3 are $66 \%$ sequence identical, we modeled the structure of DENpro on the crystal structure 3U1I of serotype $3 .{ }^{27}$ Among 100 very similar homology models, we selected the best model based on the DOPE score, ${ }^{41}$ which had a C $\alpha$-RMSD of $0.7 \AA$ relative to the crystal structure 3 U1I. 
The $\Delta \chi$ tensors associated with the $\mathrm{C} 2-\mathrm{Tm}^{3+}$ and $\mathrm{C} 2-\mathrm{Tb}^{3+}$ tags at sites A-C produce different PCSs at different sites of the DENpro-ligand complex. Using the $\Delta \chi$ tensors determined for the best-fitting model of DENpro, we predicted the PCSs for every point of a dense grid placed over the structural model of DENpro to identify all the points that were in agreement with the PCSs generated by the $\mathrm{C} 2-\mathrm{Tm}^{3+}$ and $\mathrm{C} 2-\mathrm{Tb}^{3+}$ tags at sites A-C.

Allowing for an uncertainty range of $\pm 0.02 \mathrm{ppm}$ for the experimental PCSs, the PCSs of the tert-butyl group of the ligand identified a continuous space in the vicinity of NS2B, where the tert-butyl group could be located. We refer to this PCS-supported grid point volume as localization space. The localization space of the tert-butyl group was in full agreement with its expected position upon formation of a covalent bond between Ser135 and the boronic acid moiety of the ligand, as anticipated in the design of the ligand. The localization space shown in Figure 4 was further restricted by imposing the $20 \AA$ distance restraint from the metal position of the tag at site $B$, which had been derived from PREs.

To generate a complete model of the ligand, 20 poses of ligand $\mathbf{1}$ were generated on the structural model of DENpro using the program AutoDock-Vina. ${ }^{42}$ The different poses produced dramatically different ligand structures and orientations (with a pairwise RMSD of about $10 \AA$ ) with very similar calculated binding energies (ranging from -7.5 to -7.9 $\mathrm{kcal} / \mathrm{mol}$ ). The two top-ranked and seven further poses approximately positioned the tert-butyl group in the localization space defined by the PCSs. Furthermore, the top-ranked pose positioned the boronic acid group in the vicinity of Ser135 and the direction of the tert-butylphenyl group was also in general agreement with the localization spaces of the $1 / 1^{\prime}$ and $2 / 2$ ' protons (Figure 4 ). To refine this model of the protein-ligand complex, we used the Rosetta software suite $^{38,43}$ to form a covalent bond between the boron of the ligand and the side chain oxygen of Ser135, and allowed small structural adjustments by the all-atom 'Relax' refinement protocol of Rosetta. The protocol generated 1000 structures of the complex, all with conserved protein conformations and similar ligand conformations (over 90\% within $1.3 \AA$ of the structure with the lowest PCS energy, Figure S6). The protein structure with the lowest PCS score showed an excellent correlation between the experimental and back-calculated PCSs (Figure S7). Figure 4 shows the structure best fulfilling the PCSs of DENpro, which was chosen as the final representation of the DENpro-ligand 1 complex.

The localization spaces of protons $1 / 1^{\prime}$ and $2 / 2$ ' (Figure 4) are progressively closer to the site $\mathrm{B}$, reflecting the large PCSs induced by $\mathrm{C} 2$ tags at this site (Figure $3 \mathrm{~B}$ ). This provides strong support for the orientation of the tert-butyl phenyl group. The apparent discrepancies between experimental localization spaces and actual proton positions in the model of Figure 4 may arise from mobility of the tag at site B, which can increase the PCSs by transiently shortening the distance between metal and ligand. As PCSs present longrange restraints, experimental uncertainties translate into relatively large uncertainties for localization spaces. Therefore, we used the intermolecular NOEs observed with the tert-butyl group to verify the correctness of the model of the complex.

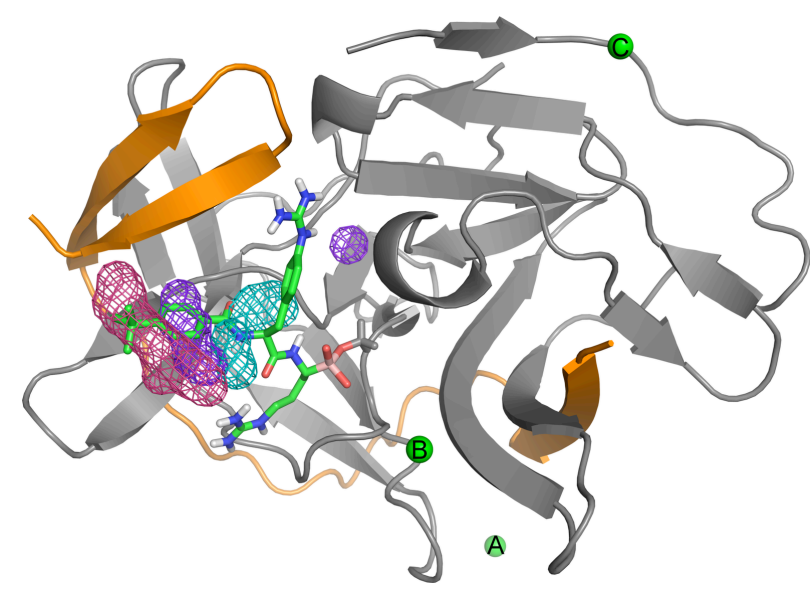

Figure 4. Model of the complex between DENpro and ligand 1. NS2B (orange) and NS3pro (grey) are drawn in a cartoon representation, and ligand $\mathbf{1}$ is shown in a stick representation, displaying hydrogens only for amide and guanidinium groups. Green balls indicate the positions of the lanthanide ions as determined by PCSs for the tags at sites A-C. Meshes identify the localization spaces of the tert-butyl group (magenta), protons $1 / 1$ ' (purple), and protons 2/2' (cyan) identified by PCSs from $\mathrm{C} 2-\mathrm{Tm}^{3+}$ and $\mathrm{C} 2-\mathrm{Tb}^{3+}$ tags at sites A-C. The meshes capture localization spaces with PCS deviations smaller than $0.02 \mathrm{ppm}$ from the experimental PCSs.

Verification of the structural model by intermolecular NOEs. The model of the complex between DENpro and ligand 1 predicts intermolecular NOEs between the tertbutyl group and the methyl groups of Val154 and Val155. The chemical shifts of the NOEs observed with the signals of $\mathrm{CH}_{3}-1$ and $\mathrm{CH}_{3}-2$ (Figure 3) agree with expectations for valine methyl groups.

To support this assignment, we recorded a NOESY spectrum of the DENpro-ligand 1 complex in which wild-type DENpro was selectively labeled with ${ }^{13} \mathrm{C}$-valine. In the absence of ${ }^{13} \mathrm{C}$ decoupling, the NOESY cross-peaks labeled 1 and 2 in Figure 2 split by ${ }^{1} J_{\mathrm{CH}}$ coupling constants and the signal of 3 could no longer be resolved, showing that all three protons indeed belong to valine (Figure S8). To distinguish between Val154 and Val155, we measured a NOESY spectrum of the mutant Val155Ile selectively labeled with ${ }^{13} \mathrm{C}$ valine. The NOESY cross-peaks observed were in agreement with an isoleucine residue and did not split in the absence of ${ }^{13} \mathrm{C}$-decoupling, indicating that the NOEs between the tert- 
butyl group of ligand $\mathbf{1}$ and wild-type DENpro are with Val155 (Figure S9).

\section{Discussion}

The surprisingly high signal-to-noise ratio of NOESY crosspeaks with a tert-butyl group can be attributed to three factors. Most importantly, its ${ }^{1} \mathrm{H}$ NMR resonance is intrinsically narrow because of short effective rotational correlation times arising from fast methyl group rotation and rotation of the tert-butyl group. Second, the signal stands out because it corresponds to nine protons. Finally, in view of the very strong distance dependence of NOEs, a small population of a short ${ }^{1} \mathrm{H}-{ }^{1} \mathrm{H}$ distance can lead to a stronger NOE than a larger population of a slightly longer ${ }^{1} \mathrm{H}-{ }^{1} \mathrm{H}$ distance. Therefore, motions of the tert-butyl group that transiently shorten the ${ }^{1} \mathrm{H}-{ }^{1} \mathrm{H}$ distance can strongly enhance the overall NOE. In this way, NOEs can be observed for proteins of increased molecular weight, which usually display broad ${ }^{1} \mathrm{H}$ NMR lines. In fact, the broad widths of the protein resonances are an advantage in our approach, as this decreases the background of NOESY cross-peaks between other protons. The high sensitivity of the NOESY cross-peaks with the tert-butyl resonance enabled their detection in a few hours, using about $100 \mu \mathrm{M}$ solutions of the complex in $3 \mathrm{~mm}$ NMR tubes.

The attempt to use the prominence of the tert-butyl resonance in $1 \mathrm{D}^{1} \mathrm{H}$ NMR spectra for PCS measurements was compromised by too many spectral changes caused by the paramagnetic tags, including a much broader tert-butyl resonance (Figure S5). In contrast, the line-up of NOESY crosspeaks with the same tert-butyl signal delivered safe assignments of its PCSs. It is an advantage of the NOESY spectrum that different cross-peaks have different intensities, as this can be used to track the cross-peaks in the paramagnetic samples, as in the example of the aromatic peaks in Figure 3B. This makes the assignment of PCSs easier in 2D NOESY spectra than in $2 \mathrm{D}^{15} \mathrm{~N}-\mathrm{HSQC}$ spectra.

It is an important additional benefit that NOESY cross-peaks also deliver the PCSs of the interacting proton spins. While the PCSs of a ${ }^{15} \mathrm{~N}-{ }^{1} \mathrm{H}$ group tend to be very similar for the ${ }^{15} \mathrm{~N}$ and ${ }^{1} \mathrm{H}$ spins due to their close spatial proximity, the ${ }^{1} \mathrm{H}$ spins involved in a NOE are further apart and thus more likely to display PCSs of different magnitude. This presents highly useful information for orienting the inter-nuclear vector relative to the $\Delta \chi$ tensor. In the case of the tert-butyl phenyl group of ligand 1, PCSs were available from three different tagging sites, which unambiguously determined its orientation relative to the protein.

As is common with drug targets of moderate complexity, resonance assignments of DENpro could be obtained with reasonable effort for spectrally resolved ${ }^{15} \mathrm{~N}-\mathrm{HSQC}$ crosspeaks, whereas near-complete resonance assignments, as required for conventional NOESY cross-peak assignments, would be prohibitively laborious to establish for every com- plex with a new ligand. In this situation, PCSs present a much more efficient route to structural information, as $\Delta \chi$ tensors can be determined from PCSs of a small number of resolved backbone amide peaks, which can be assigned by, e.g., systematic site-directed mutagenesis of selectively isotope-labeled samples. ${ }^{50,51}$ While the accuracy of PCSs may be insufficient to predict close intermolecular protein-ligand contacts, the localization spaces defined by PCSs from paramagnetic tags at multiple sites greatly limit the number of possible assignments for intermolecular NOEs observed with the tert-butyl resonance. As shown in the present work, the residue type of the protein protons involved in the intermolecular NOEs can be ascertained by chemical shifts as well as selective isotope labeling.

In many instances, it is easier to synthesize a ligand molecule with a tert-butyl group than with a stable isotope, in particular as tert-butyl groups are part of common synthetic building blocks and protection strategies. Consequently, tert-butyl groups are also frequently found in fragment libraries and series of inhibitor candidates during the early phases of the drug discovery process. The tert-butyl moiety can establish hydrophobic protein-ligand interactions and therefore often increases ligand affinity. It is also present in recently approved drugs, such as the $\mathrm{HCV}$ protease inhibitors boceprevir and telaprevir. ${ }^{52}$ If a tert-butyl group is highly solvent exposed and flexible, it will produce less intense NOEs, but its ${ }^{1} \mathrm{H}$ NMR signal will be narrower, which facilitates identification of its localization space as a taller signal makes it easier to extract PCSs from 1D NMR spectra.

Ligands containing fluorine have found widespread application as NMR probes for protein-ligand studies. ${ }^{16,53}$ In principle, the combined PCS and NOE strategy outlined in the present work could be extended to ${ }^{1} \mathrm{H}-{ }^{19} \mathrm{~F}$ HOESY spectra, except that sensitivity would be compromised by the much broader line width of ${ }^{19} \mathrm{~F}$ combined with typically fewer ${ }^{19} \mathrm{~F}$ spins in the ligand molecules.

In conclusion, the combined PCS and NOE approach of the present work opens a practical and expedient route to elucidate the binding mode of high-affinity ligands in 1:1 complexes of protein targets. In contrast to studies with weakly binding ligands, no excess of ligand is required, which is an important advantage in the case of poorly soluble compounds. Detailed structural information about the proteinligand complex can be obtained without costly perdeuteration, and dilute solutions of protein-ligand complexes with highly incomplete NMR resonance assignments can be investigated. While multiple samples with different paramagnetic tags are required to measure the PCSs and NOEs, each NMR experiment is quick and uses protein sparingly, making it practical to study a protein with a set of different ligands. The structural data that can be obtained with this strategy open a new and unique window of opportunity for the rational development of high-affinity lead compounds in drug development projects, when co-crystal structures of the pro- 
tein-ligand complex cannot be obtained with acceptable effort.

\section{ASSOCIATED CONTENT}

Supporting Information. Tables of PCSs; table of fitted $\Delta \chi$ tensor parameters; chemical structure of the C2- $\mathrm{Ln}^{3+}$ tag; comparison of ${ }^{15} \mathrm{~N}$-HSQC spectra of DENpro with and without ligand 1 ; ${ }^{15} \mathrm{~N}-\mathrm{HSQC}$ spectrum with resonance assignments; ${ }^{15} \mathrm{~N}-\mathrm{HSQC}$ spectra of DENpro tagged with $\mathrm{C} 2-\mathrm{Y}^{3+}, \mathrm{C} 2-\mathrm{Tm}^{3+}$, and $\mathrm{C} 2-\mathrm{Tb}^{3+}$ at different sites; $1 \mathrm{D}{ }^{1} \mathrm{H}$ NMR spectra showing PCSs of the tert-butyl group of ligand $\mathbf{1}$ in complex with DENpro; RMSDs of ligand poses after Rosetta refinement; correlation between experimental and back-calculated PCSs for the final model structure of DENpro; NOESY spectra recorded with and without ${ }^{13} \mathrm{C}$-decoupling; NOESY spectrum of DENpro Val155Ile; comparison between the structural model of the complex between DENpro and ligand $\mathbf{1}$ of the present work with the crystal structure $3 \mathrm{U} 1 \mathrm{I}$.

\section{AUTHOR INFORMATION}

\section{Corresponding Author}

*gottfried.otting@anu.edu.au

\section{ACKNOWLEDGMENT}

Financial support by the Australian Research Council is gratefully acknowledged. C. D. K. appreciates financial support by the Deutsche Forschungsgemeinschaft (grant KL-1356/3-1). W.-N. C. thanks the government of the People's Republic of China for a CSC scholarship. C. N. thanks the Alexander von Humboldt Foundation for a Feodor Lynen fellowship.

\section{REFERENCES}

(1) (a) Barile, E.; Pellecchia, M. Chem. Rev. 2014, 114, 4749-4763. (b) Harner M. J.; Frank, A. O.; Fesik, S. W. J. Biomol. NMR 2013, 56, 6575. (c) Pellecchia, M.; Sem, D. S.; Wüthrich, K. Nat. Rev. Drug Discovery 2002, 1, 211-219. (d) Hajduk, P. J.; Meadows, R. P.; Fesik, S. W. Quart. Rev. Biophys. 1999, 32, 211-240. (e) Otting, G. Curr. Opin. Struct. Biol. 1993, 3, 760-768.

(2) (a) Shuker, S. B.; Hajduk, P. J.; Meadows, R. P.; Fesik, S. W. Science 1996, 274, 1531-1534. (b) Medek, A.; Hajduk, P. J.; Mack, J.; Fesik, S. W. J. Am. Chem. Soc. 2000, 122, 1241-1242.

(3) (a) Breeze, A. L. Prog. NMR Spectrosc. 2000, 36, 323-372. (b) Eichmüller, C.; Tollinger, M.; Kräutler, B.; Konrat, R. J. Biomol. NMR 2001, 20, 195-202.

(4) Pellecchia, M.; Meininger, D.; Dong, Q.; Chang, E.; Jack, R.; Sem, D. S. J. Biomol. NMR 2002, 22, 165-173.

(5) (a) Liu, W. M.; Overhand, M.; Ubbink, M. Coord. Chem. Rev. 2014, 273-274, 2-12. (b) Otting, G. Annu. Rev. Biophys. 2010, 39, 387-405. (c) Otting, G. J. Biomol. NMR 2008, 42, 1-9.

(6) John, M.; Pintacuda, G.; Park, A. Y.; Dixon, N. E.; Otting, G. J. Am. Chem. Soc. 2006, 128, 12910-12916.

(7) Pintacuda, G.; John, M.; Su, X.-C.; Otting, G. Acc. Chem. Res. 2007, 40, 206-212.

(8) Zhuang, T.; Lee, H.-S.; Imperiali, B.; Prestegard, J. H. Protein Sci. 2008, 17, 1220-1231.
(9) Balogh, E.; Wu, D.; Zhou, G.; Gochin, M. J. Am. Chem. Soc. 2009, 131, 2821-2823.

(10) Keizers, P. H. J.; Mersinli, B.; Reinle, W.; Donauer, J.; Hiruma, Y.; Hannemann, F.; Overhand, M.; Bernhardt, R.; Ubbink, M. Biochemistry 2010, 49, 6846-6855.

(11) Saio, T.; Ogura, K.; Shimizu, K.; Yokochi, M.; Burke, T. R.; Inagaki, F. J. Biomol. NMR 201 1, 51, 395-408.

(12) Guan, J.; Keizers, P. H. J.; Liu, W.; Löhr, F.; Skinner, S. P.; Heeneman, E. A.; Schwalbe, H.; Ubbink, M.; Siegal, G. J. Am. Chem. Soc. 2013, 135, 5859-5868.

(13) Saio, T.; Yokochi, M.; Kumeta, H.; Inagaki, F. J. Biomol. NMR 2010, 46, 271-280.

(14) Canales, A.; Mallagaray, A.; Berbís, M. A.; Navarro-Vázquez, A.; Domínguez, G.; Cañada, F. J.; André, S.; Gabius, H. J.; Pérez-Castells, J.; Jiménez-Barbero, J. J. Am. Chem. Soc. 2014, 136, 8011-8017.

(15) Brath, U.; Swamy, S. I.; Veiga, Z. X.; Tung, C.-C.; Van Petegem, F.; Erdélyi, M. J. Am. Chem. Soc. 2015, 137, 11391-11398.

(16) Poppe, L.; Tegley, C. M.; Li, V.; Lewis, J.; Zondlo, J.; Yang, E.; Kurzeja, R. J.; Syed, R. J. Am. Chem. Soc. 2009, 131, 16654-16655.

(17) Chen, W. N.; Loscha, K. V.; Nitsche, C.; Graham, B.; Otting, G. FEBS Lett. 2014, 588, 2206-2211.

(18) (a) Otting, G.; Wüthrich, K. Quart. Rev. Biophys. 1990, 23, 3996. (b) Zwahlen, C.; Legault, P.; Vincent S. J. F.; Greenblatt, J.; Konrat, R.; Kay, L. E. J. Am. Chem. Soc. 1997, 119, 6711-6721. (c) Whitehead, B.; Tessari, M.; Düx, P.; Boelens, R.; Kaptein, R.; Vuister, G. W. J. Biomol. NMR 1997, 9, 313-316. (d) Sattler, M.; Schleucher, J.; Griesinger, C. Prog. NMR Spectrosc. 1999, 34, 93-158. (e) Andersson, P.; Otting, G. J. Magn. Reson. 2000, 144, 168-170.

(19) Hsu, V. L.; Armitage, I. M. Biochemistry 1992, 31, 1277812784.

(20) Chen, W.-N.; Kuppan, K. V.; Lee, M. D.; Jaudzems, K.; Huber, T.; Otting, G. J. Am. Chem. Soc. 2015, 137, 4581-4586.

(21) Capeding, M. R.; Tran, N.H.; Hadinegoro, S. R.; Ismail, H. I.; Chotpitayasunondh, T.; Chua, M. N.; Luong, C. Q.; Rusmil, K.; Wirawan, D. N.; Nallusamy, R.; Pitisuttithum, P.; Thisyakorn, U.; Yoon, I. K.; van der Vliet, D.; Langevin, E.; Laot, T.; Hutagalung, Y.; Frago, C.; Boaz, M.; Wartel, T. A.; Tornieporth, N. G.; Saville, M.; Bouckenooghe, A. Lancet 2014, $384,1358-1365$.

(22) (a) Messina, J. P.; Brady, O. J.; Scott, T. W.; Zou, C.; Pigott, D. M.; Duda, K. A.; Bhatt, S.; Katzelnick, L.; Howes, R. E.; Battle, K. E.; Simmons, C. P.; Hay, S. I. Trends Microbiol. 2014, 22, 138-146. (b) Screaton, G.; Mongkolsapaya, J.; Yacoub, S.; Roberts, C. Nat. Rev. Immunol. 2015, 15, 745-759.

(23) Clum, S.; Ebner, K. E.; Padmanabhan, R. J. Biol. Chem. 1997, 272, 30715-30723.

(24) Lescar, J.; Luo, D.; Xu, T.; Sampath, A.; Lim, S.; Canard, B.; Vasudevan, S. Antiviral Res. 2008, 80, 94-101.

(25) (a) Nitsche, C.; Holloway, S.; Schirmeister, T.; Klein, C. D. Chem. Rev. 2014, 114, 11348-11381. (b) Behnam, M. A. M.; Nitsche, C.; Boldescu, V.; Klein, C. D. J. Med. Chem. 2016, doi: 10.1021/acs.jmedchem.5b01653.

(26) Erbel, P.; Schiering, N.; D’Arcy, A.; Renatus, M.; Kroemer, M.; Lim, S. P.; Yin, Z.; Keller, T. H.; Vasudevan, S. G.; Hommel, U. Nat. Struct. Mol. Biol. 2006, 13, 372-373.

(27) Noble, C. G.; Seh, C. C.; Chao, A. T.; Shi, P. Y. J. Virol. 2012, $86,438-446$.

(28) Yin, Z.; Patel, S. J.; Wang, W.-L.; Wang, G.; Chan, W.-L.; Rao, K. R. R.; Alam, J.; Jeyaraj, D. A; Ngew, X.; Patel, V.; Beer, D.; Lim, S. P.; Vasudevan, S. G.; Keller, T. H. Bioorg. Med. Chem. Lett. 2006, 16, 36-39.

(29) Nitsche, C.; Schreier, V. N.; Behnam, M. a M.; Kumar, A.; Bartenschlager, R.; Klein, C. D. J. Med. Chem. 2013, 56, 8389-8403.

(30) Lim, S. P.; Wang, Q. Y.; Noble, C. G.; Chen, Y. L.; Dong, H.; Zou, B.; Yokokawa, F.; Nilar, S.; Smith, P.; Beer, D.; Lescar, J.; Shi, P. Y. Antiviral Res. 2013, 100, 500-519.

(31) de la Cruz, L.; Nguyen, T. H. D.; Ozawa, K.; Shin, J.; Graham, B.; Huber, T.; Otting, G. J. Am. Chem. Soc. 2011, 133, 19205-19215.

(32) Kim, Y. M.; Gayen, S.; Kang, C.; Joy, J.; Huang, Q.; Chen, A. S.; Wee, J. L.; Ang, M. J.; Lim, H. A.; Hung, A. W.; Li, R.; Noble, C. G.; Lee, L. 
T.; Yip, A.; Wang, Q.-Y.; Chia, C. S. B.; Hill, J.; Shi, P.-Y.; Keller, T. H. J. Biol. Chem. 2013, 288, 12891-12900.

(33) Bi, Y.; Zhu, L.; Li, H.; Wu, B.; Liu, J.; Wang, J. Biomol. NMR Assign. 2013, 7, 137-139.

(34) Li, H.; Zhu, L.; Hou, S.; Yang, J.; Wang, J.; Liu, J. FEBS Lett. 2014, 588, 2794-2799.

(35) de la Cruz, L.; Chen, W. N.; Graham, B.; Otting, G. FEBS J. 2014, 281, 1517-1533.

(36) Graham, B.; Loh, C. T.; Swarbrick, J. D.; Ung, P.; Shin, J.; Yagi, H.; Jia, X.; Chhabra, S.; Barlow, N.; Pintacuda, G.; Huber, T.; Otting, G. Bioconjug. Chem. 2011, 22, 2118-2125.

(37) Bertini, I.; Luchinat, C.; Parigi, G. Prog. Nucl. Magn. Reson. Spectrosc. 2002, 40, 249-273.

(38) Pilla, K. B.; Leman, J. K.; Otting, G.; Huber, T. PLoS One 2015, 10, $\mathrm{e} 0127053$.

(39) Šali, A.; Blundell, T. L. J. Mol. Biol. 1993, 234, 779-815.

(40) Webb, B.; Sali, A. In Protein Structure Prediction; Springer, 2014; pp $1-15$.

(41) Shen, M.; Sali, A. Protein Sci. 2006, 15, 2507-2524.

(42) Trott, O.; Olson, A. J. J. Comput. Chem. 2010, 31, 455-461.
(43) Conway, P.; Tyka, M. D.; DiMaio, F.; Konerding, D. E.; Baker, D. Protein Sci. 2014, 23, 47-55.

(44) Venkatraman, S.; Wu, W.; Prongay, A.; Girijavallabhan, V.; Njoroge, F. G. Bioorg. Med. Chem. Lett. 2009, 19, 180-183.

(45) www.rosettacommons.org/demos/latest/public/relax_around _chemically_bound_ligand/README, accessed 1 Nov. 2014.

(46) Schmitz, C.; Vernon, R.; Otting, G.; Baker, D.; Huber, T. J. Mol. Biol. 2012, 416, 668-677.

(47) Bleaney, B. J. Magn. Reson. 1972, 8, 91-100.

(48) Vega, A. J.; Fiat, D. Mol. Phys. 1976, 31, 347-355.

(49) Pintacuda, G.; Kaikkonen, A.; Otting, G. J. Magn. Reson. 2004, 171, 233-243.

(50) Wu, P. S. C.; Ozawa, K.; Lim, S. P.; Vasudevan, S. G.; Dixon, N. E.; Otting, G. Angew. Chemie Int. Ed. 2007, 46, 3356-3358.

(51) Abdelkader, E. H.; Yao, X.; Feintuch, A.; Adams, L. A.; Aurelio, L.; Graham, B.; Goldfarb, D.; Otting, G. J. Biomol. NMR 2016, 64, 39-51.

(52) De Luca, A.; Bianco, C.; Rossetti, B. Curr. Opin. Pharmacol. 2014, 18, 9-17.

(53) Vulpetti, A.; Dalvit, C. Drug Discov. Today 2012, 17, 890-897.

TOC

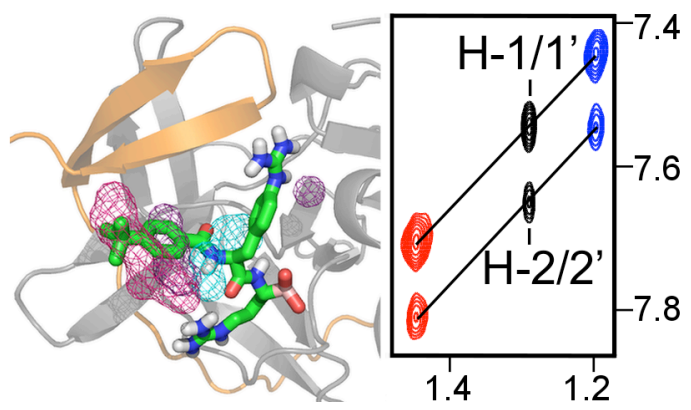




\section{Supporting information}

Sensitive NMR Approach for Determining the Binding Mode of Tightly Binding Ligand Molecules to Protein Targets

Wan-Na Chen, Christoph Nitsche, Kala Bharath Pilla, Bim Graham, Thomas Huber, Christian D. Klein, Gottfried Otting* 
Table S1. PCSs measured of backbone amide protons of DENpro in complex with ligand $\mathbf{1}{ }^{\mathrm{a}}$

\begin{tabular}{|c|c|c|c|c|c|c|}
\hline \multirow{2}{*}{ Residue } & \multicolumn{2}{|c|}{ Site A } & \multicolumn{2}{|c|}{ Site B } & \multicolumn{2}{|c|}{ Site C } \\
\hline & $\mathrm{Tm}^{3+}$ & $\mathrm{Tb}^{3+}$ & $\mathrm{Tm}^{3+}$ & $\mathrm{Tb}^{3+}$ & $\mathrm{Tm}^{3+}$ & $\mathrm{Tb}^{3+}$ \\
\hline \multicolumn{7}{|l|}{ NS2B } \\
\hline Ser70* & -0.35 & 0.46 & -0.06 & 0.08 & -0.01 & 0 \\
\hline Ser71* & -0.26 & 0.33 & -0.05 & 0.06 & -0.02 & 0.02 \\
\hline Ile73* & - & - & -0.05 & 0.07 & -0.08 & 0.09 \\
\hline Leu74* & -0.12 & 0.18 & -0.06 & 0.09 & -0.05 & 0.08 \\
\hline Ser75* & -0.09 & 0.11 & -0.06 & 0.08 & -0.06 & 0.09 \\
\hline Ile78* & -0.07 & - & -0.11 & 0.17 & -0.09 & 0.20 \\
\hline Ser79* & -0.01 & 0.02 & -0.21 & 0.25 & -0.23 & 0.34 \\
\hline Asp81* & - & - & - & 0.33 & -0.34 & -0.54 \\
\hline Gly82* & - & - & -0.26 & 0.33 & -0.37 & 0.58 \\
\hline Ser83* & - & - & -0.34 & 0.42 & -0.31 & 0.48 \\
\hline Ser85* & -0.03 & 0.05 & -0.16 & 0.20 & -0.14 & 0.21 \\
\hline Ile86* & -0.05 & - & -0.11 & 0.12 & -0.09 & 0.14 \\
\hline Lys87* & -0.05 & 0.08 & -0.07 & 0.08 & -0.08 & 0.11 \\
\hline \multicolumn{7}{|l|}{ NS3pro } \\
\hline Gly21 & 0.58 & - & 0.16 & -0.19 & - & - \\
\hline Ala22 & - & - & 0.18 & -0.22 & - & - \\
\hline Tyr23 & - & - & 0.32 & -0.38 & - & - \\
\hline Lys28 & - & - & - & - & 0.31 & -0.53 \\
\hline Ser34 & - & - & - & - & 0.21 & - \\
\hline
\end{tabular}




\begin{tabular}{|c|c|c|c|c|c|c|}
\hline Gly39 & 0.83 & -0.99 & 0.37 & -0.44 & 0.49 & -0.76 \\
\hline Tyr41 & 0.59 & -0.72 & 0.20 & -0.23 & 0.56 & -0.84 \\
\hline Lys42 & 0.20 & -0.25 & 0.15 & -0.17 & - & - \\
\hline Glu43 & 0.04 & -0.06 & 0.10 & -0.12 & - & - \\
\hline Gly44 & 0.14 & -0.19 & 0.12 & -0.16 & - & - \\
\hline Phe46 & 0.26 & -0.30 & 0.20 & -0.23 & - & - \\
\hline $\operatorname{Trp} 50$ & 0.10 & -0.12 & - & - & - & - \\
\hline His51 & 0.12 & -0.14 & - & - & -0.32 & 0.05 \\
\hline Val52 & 0.19 & -0.23 & - & - & -0.03 & - \\
\hline Thr53 & 0.24 & -0.29 & - & - & 0.14 & -0.26 \\
\hline Gly55 & 0.19 & -0.23 & - & - & - & - \\
\hline Gly62 & 0.47 & -0.58 & 0.38 & -0.44 & - & -1.26 \\
\hline Glu66 & 0.23 & - & 0.24 & - & - & - \\
\hline Ala70 & 0.05 & -0.05 & -0.05 & 0.05 & - & - \\
\hline Ser78 & - & - & 0.06 & -0.07 & - & - \\
\hline Gly81 & 0.14 & -0.15 & 0.12 & -0.16 & - & - \\
\hline Gly82 & 0.05 & -0.06 & 0.07 & -0.08 & - & - \\
\hline Leu85 & - & 0.10 & 0.05 & -0.04 & - & - \\
\hline Trp89 & - & - & -0.03 & 0.03 & -0.06 & 0.08 \\
\hline Gly92 & -0.28 & 0.37 & - & - & -0.03 & 0.04 \\
\hline Gln96 & - & - & - & - & 0.04 & -0.07 \\
\hline Leu98 & -1.15 & - & - & - & 0.10 & -0.17 \\
\hline Leu100 & - & - & - & - & 0.17 & -0.26 \\
\hline
\end{tabular}




\begin{tabular}{|c|c|c|c|c|c|c|}
\hline Gly103 & - & - & - & - & 0.16 & -0.26 \\
\hline Gln 110 & - & - & -0.03 & 0.05 & 0.03 & -0.06 \\
\hline Thr111 & - & 1.18 & -0.04 & 0.06 & - & - \\
\hline Gly114 & -0.28 & - & -0.08 & 0.08 & - & - \\
\hline Phe116 & -0.15 & 0.21 & -0.09 & 0.10 & -0.08 & 0.11 \\
\hline Lys 117 & - & - & -0.08 & 0.09 & -0.07 & 0.11 \\
\hline Thr120 & -0.06 & 0.08 & -0.07 & 0.09 & -0.12 & 0.19 \\
\hline Gly121 & -0.07 & 0.10 & -0.06 & 0.08 & -0.11 & 0.15 \\
\hline Thr122 & - & - & -0.05 & 0.07 & -0.10 & 0.14 \\
\hline Ile123 & - & - & - & - & -0.12 & 0.11 \\
\hline Ser127 & -0.36 & - & -0.09 & 0.11 & - & - \\
\hline Val140 & - & - & - & - & 0.06 & -0.10 \\
\hline Gly 148 & -0.38 & 0.49 & - & - & 0.02 & -0.06 \\
\hline Ala160 & -0.11 & 0.15 & -0.04 & 0.05 & -0.03 & 0.05 \\
\hline Ala164 & - & - & -0.22 & 0.28 & -0.08 & 0.12 \\
\hline Ile165 & - & - & -0.12 & 0.14 & - & - \\
\hline Ala166 & - & - & -0.08 & - & -0.08 & 0.13 \\
\hline
\end{tabular}

${ }^{\text {a }}$ PCSs were generated by $\mathrm{C} 2-\mathrm{Tm}^{3+}$ and $\mathrm{C} 2-\mathrm{Tb}^{3+}$ tags at sites A-C. Corresponding samples with $\mathrm{C} 2-\mathrm{Y}^{3+}$ tags were used as the diamagnetic reference. PCSs are reported in ppm as the ${ }^{1} \mathrm{H}$ chemical shift measured in the presence of paramagnetic tag minus the ${ }^{1} \mathrm{H}$ chemical shift measured of the diamagnetic reference. 
Table S2. PCSs observed in NOESY spectra of the complex between ligand 1 and DENpro with $\mathrm{C} 2-\operatorname{Ln}^{3+} \operatorname{tags}^{\mathrm{a}}$

\begin{tabular}{|c|c|c|c|c|c|c|}
\hline \multirow[b]{2}{*}{$\begin{array}{c}\text { Tag site and } \\
\text { metal }\end{array}$} & \multicolumn{3}{|c|}{ Ligand 1} & \multicolumn{3}{|c|}{ Protein } \\
\hline & $\begin{array}{c}\text { tert-butyl } \\
\text { group } \\
(\mathrm{ppm})\end{array}$ & $\begin{array}{l}\mathrm{H}-1 / 1 \text { ' } \\
(\mathrm{ppm})\end{array}$ & $\begin{array}{l}\mathrm{H}-2 / 2 \text { ' } \\
(\mathrm{ppm})\end{array}$ & $\begin{array}{l}\mathrm{CH}_{3}-1 \\
(\mathrm{ppm})\end{array}$ & $\begin{array}{l}\mathrm{CH}_{3}-2 \\
(\mathrm{ppm})\end{array}$ & $\begin{array}{c}\mathrm{H}-3 \\
\text { (ppm) }\end{array}$ \\
\hline $\mathrm{A}-\mathrm{Tm}^{3+}$ & -0.01 & 0.00 & 0.00 & -0.05 & -0.06 & -0.05 \\
\hline $\mathrm{A}-\mathrm{Tb}^{3+}$ & 0.02 & 0.01 & 0.01 & 0.07 & 0.09 & 0.08 \\
\hline $\mathrm{B}-\mathrm{Tm}^{3+}$ & -0.09 & -0.27 & -0.56 & -0.14 & n.d. & n.d. \\
\hline $\mathrm{B}-\mathrm{Tb}^{3+}$ & 0.10 & 0.33 & 0.67 & 0.15 & n.d. & n.d. \\
\hline $\mathrm{C}-\mathrm{Tm}^{3+}$ & -0.10 & -0.10 & -0.10 & -0.06 & -0.05 & -0.06 \\
\hline $\mathrm{C}-\mathrm{Tb}^{3+}$ & 0.16 & 0.16 & 0.16 & 0.09 & 0.07 & 0.10 \\
\hline $\begin{array}{c}\text { Chemical } \\
\text { shift }^{\mathrm{a}}\end{array}$ & 1.30 & 7.54 & 7.66 & 0.67 & 0.78 & 1.73 \\
\hline
\end{tabular}

${ }^{\text {a }}$ Measured for the complex of ligand 1 with wild-type DENpro without tag. See Figures $1 \mathrm{~A}$ and 2B for the numbering of the proton resonances. n.d., not detected. 
Table S3. $\Delta \chi$ tensor parameters fitted to the homology model built of DENpro and refined by Rosetta $^{\mathrm{a}}$

\begin{tabular}{ccccccccc}
\hline $\begin{array}{c}\text { Tagging site and } \\
\text { metal }\end{array}$ & $\Delta \chi_{\mathrm{ax}}$ & $\Delta \chi_{\mathrm{rh}}$ & $\mathrm{x}$ & $\mathrm{y}$ & $\mathrm{z}$ & $\alpha$ & $\beta$ & $\gamma$ \\
\hline${\mathrm{A}-\mathrm{Tm}^{3+}}^{3+}$ & 17.1 & 6.7 & 16.415 & -18.172 & 36.099 & 140.1 & 139.5 & 38.5 \\
${\mathrm{~A}-\mathrm{Tb}^{3+}}^{3}$ & -21.1 & -8.3 & 16.415 & -18.172 & 36.099 & 141.4 & 139.8 & 42.7 \\
${\mathrm{~B}-\mathrm{Tm}^{3+}}^{3}$ & 8.7 & 2.0 & 8.634 & -21.149 & 7.976 & 102.9 & 54.8 & 43.0 \\
${\mathrm{~B}-\mathrm{Tb}^{3+}}^{3}$ & -10.5 & -2.7 & 8.634 & -21.149 & 7.976 & 102.5 & 56.8 & 41.8 \\
${\mathrm{C}-\mathrm{Tm}^{3+}}^{17.7}$ & 3.5 & 13.935 & 4.362 & 4.462 & 49.3 & 147.9 & 82.2 \\
${\mathrm{C}-\mathrm{Tb}^{3+}}^{2}$ & -27.4 & -6.9 & 13.935 & 4.362 & 4.462 & 49.3 & 147.9 & 82.2 \\
\hline
\end{tabular}

${ }^{a}$ The tensor parameters are reported with respect to the final Rosetta-refined model, which is available from http://rsc.anu.edu.au/ go/coordinates/. The axial and rhombic components of the $\Delta \chi$ tensors are given in $10^{-32} \mathrm{~m}^{3}$ and the Euler angles in degrees, using the zyz convention and unique tensor representation. ${ }^{1} \Delta \chi$ tensor fits were performed by restricting $\mathrm{Tb}^{3+}$ and $\mathrm{Tm}^{3+}$ to the same site. 


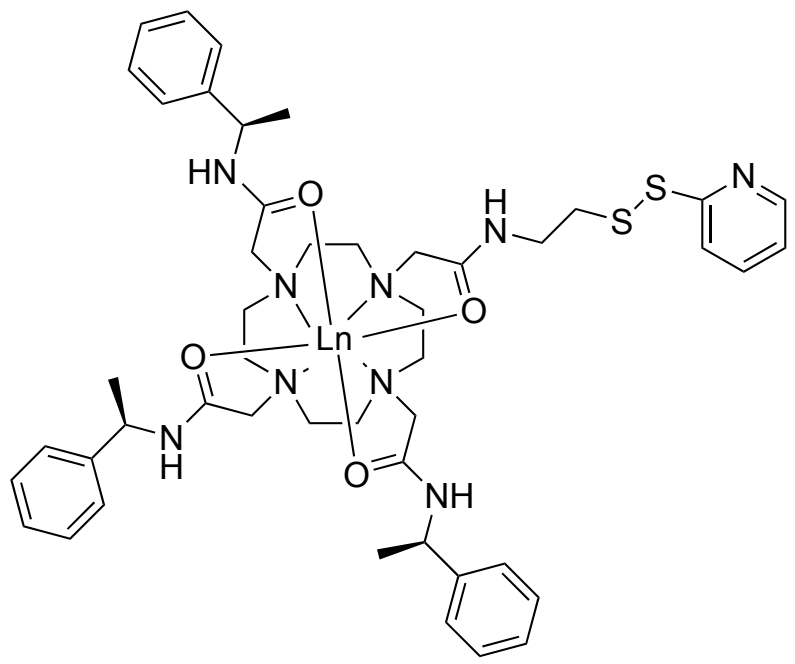

Figure S1. Chemical structure of the $\mathrm{C} 2-\mathrm{Ln}^{3+}$ tag. ${ }^{2}$ 


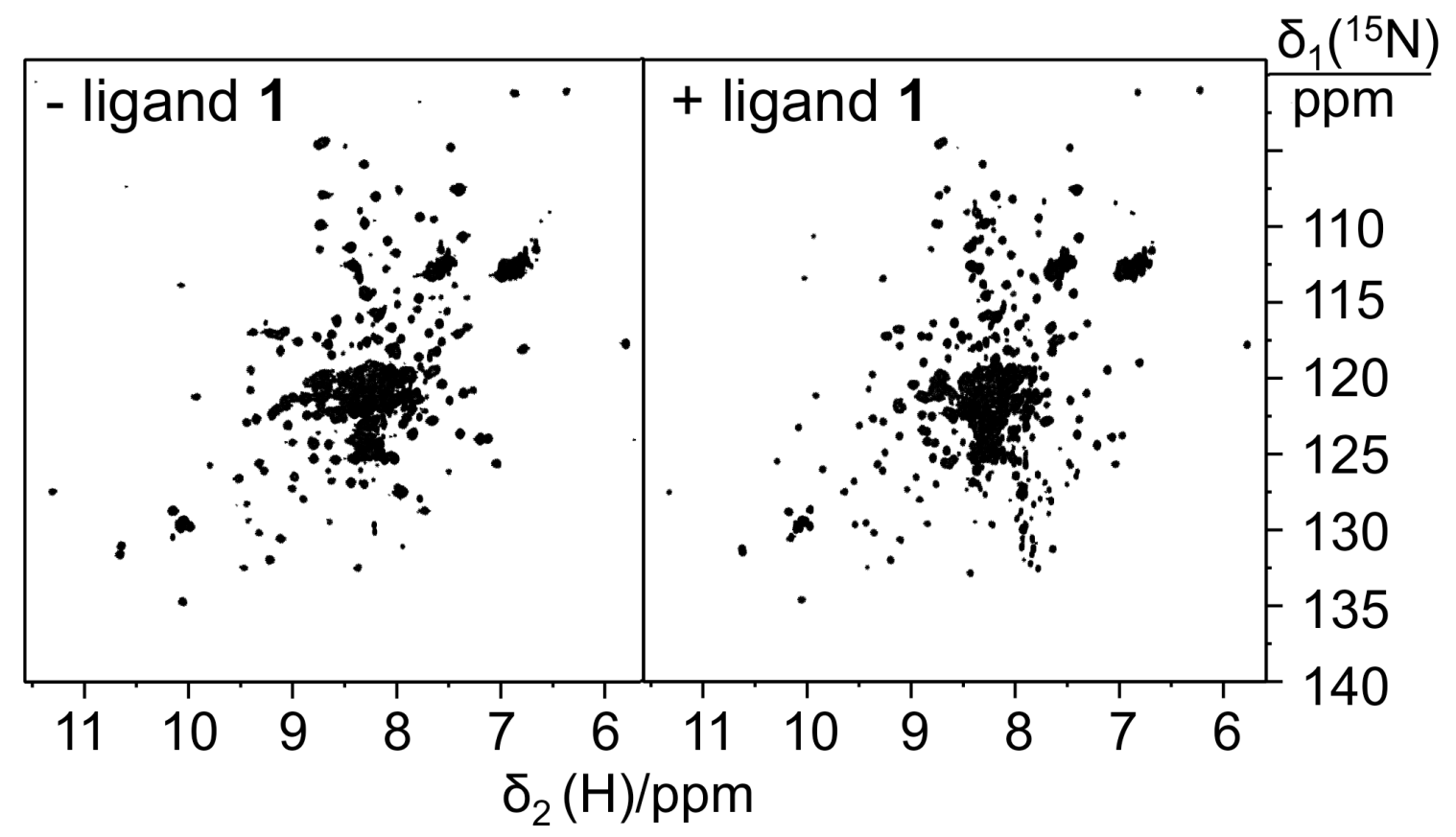

Figure S2. ${ }^{15} \mathrm{~N}-\mathrm{HSQC}$ spectra of DENpro without (left spectrum) and with ligand 1 (right spectrum). The spectra were recorded of $150 \mu \mathrm{M}$ solutions of uniformly ${ }^{15} \mathrm{~N}$-labeled DENpro tagged at site $\mathrm{B}$ with a diamagnetic $\mathrm{C} 2-\mathrm{Y}^{3+}$ tag. The comparison shows that many of the wellresolved peaks can be tracked despite some changes in chemical shifts. 


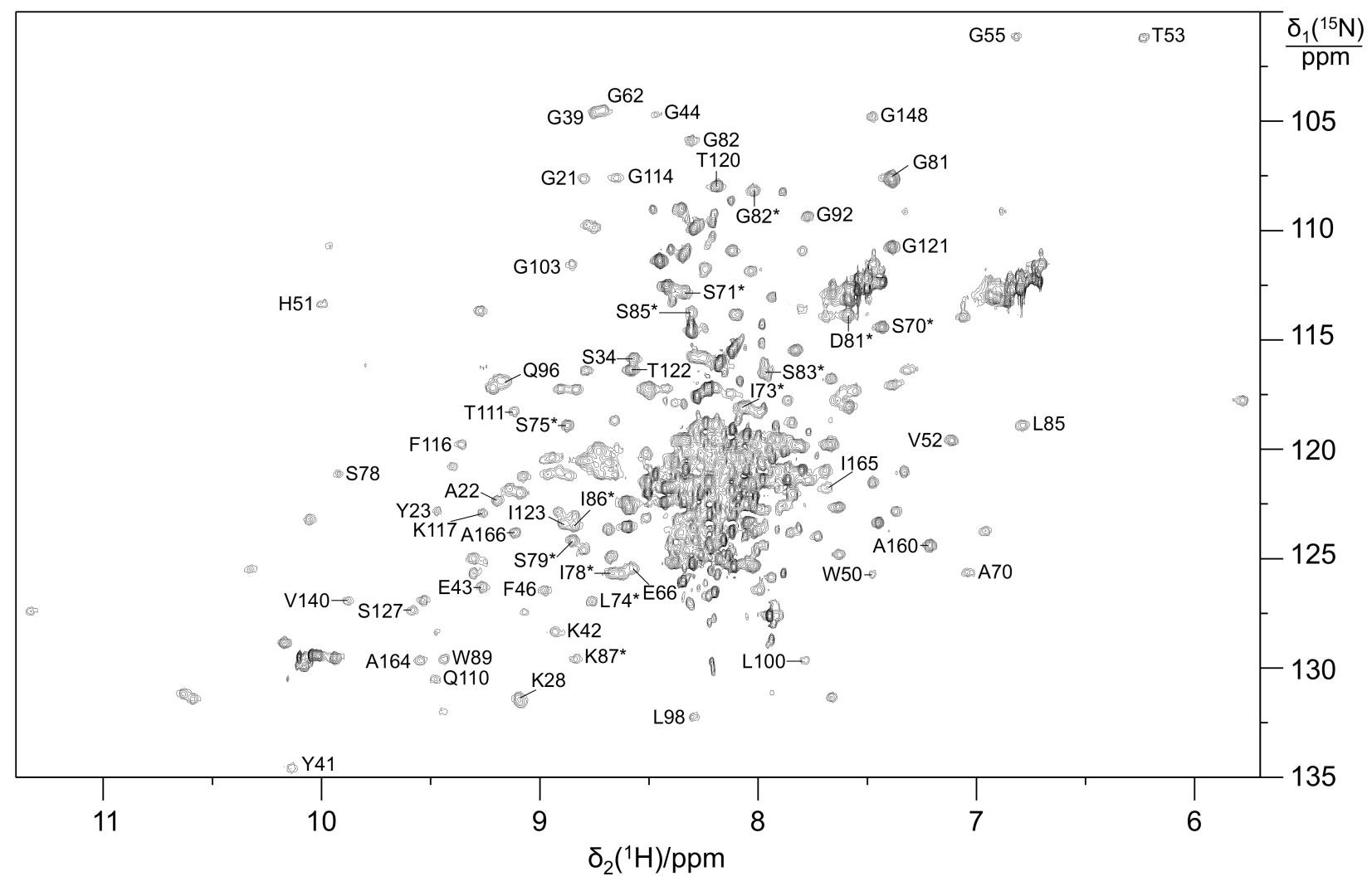

Figure S3. ${ }^{15} \mathrm{~N}-\mathrm{HSQC}$ spectrum recorded of a $150 \mu \mathrm{M}$ solution of uniformly ${ }^{15} \mathrm{~N}$-labeled DENpro tagged at site A with a diamagnetic $\mathrm{C} 2-\mathrm{Y}^{3+}$ tag and in complex with ligand 1. Solution conditions: $20 \mathrm{mM}$ MES, pH 6.5, $50 \mathrm{mM} \mathrm{NaCl}, 25{ }^{\circ} \mathrm{C}$. The spectrum was recorded using a $3 \mathrm{~mm}$ NMR tube on a Bruker $800 \mathrm{MHz}$ NMR spectrometer equipped with a TCI cryoprobe. The crosspeaks used as diamagnetic reference for PCS measurements (Table S1) are marked with their sequence-specific residue assignments. 


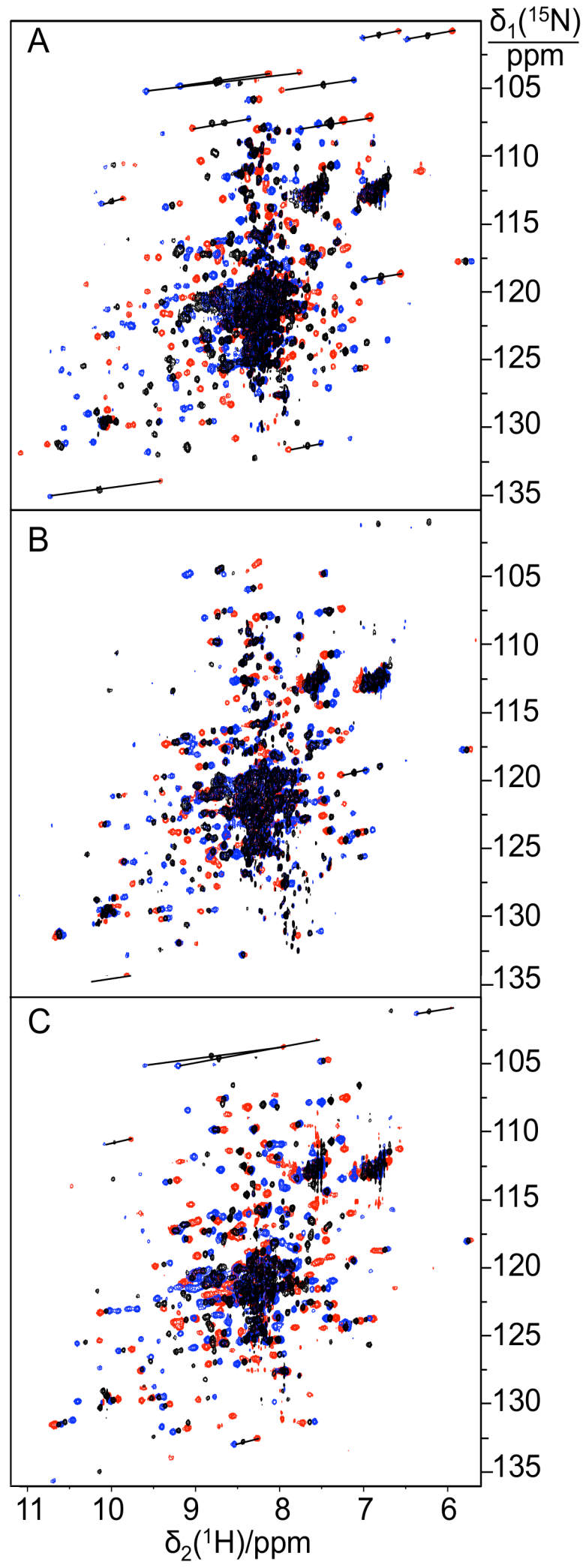

Figure S4. PCS measurements of backbone amide protons. The figure shows superimpositions of ${ }^{15} \mathrm{~N}$-HSQC spectra recorded of uniformly ${ }^{15} \mathrm{~N}$-labeled DENpro in complex with ligand $\mathbf{1}$ with 
$\mathrm{C} 2-\mathrm{Ln}^{3+}$ tags at different sites of DENpro. Panels A-C show the spectra with tags at sites A, B, and $\mathrm{C}$, respectively. Spectra of DENpro with diamagnetic tag $\left(\mathrm{C} 2-\mathrm{Y}^{3+}\right)$ are shown in black, and the corresponding spectra with paramagnetic tags are plotted in red $\left(\mathrm{C} 2-\mathrm{Tm}^{3+}\right)$ and blue $(\mathrm{C} 2-$ $\left.\mathrm{Tb}^{3+}\right)$. Selected cross-peaks are linked by lines indicating the pseudocontact shifts. The spectra were recorded of $150 \mu \mathrm{M}$ solutions of DENpro-ligand 1 complexes in NMR buffer ( $\mathrm{pH}$ 6.5) at $25{ }^{\circ} \mathrm{C}$, using a Bruker $800 \mathrm{MHz}$ NMR spectrometer. Based on the cross-peaks observed in these ${ }^{15} \mathrm{~N}-\mathrm{HSQC}$ spectra, the tag ligation yields at sites A-C were about $80 \%, 70 \%$, and $90 \%$, respectively. 

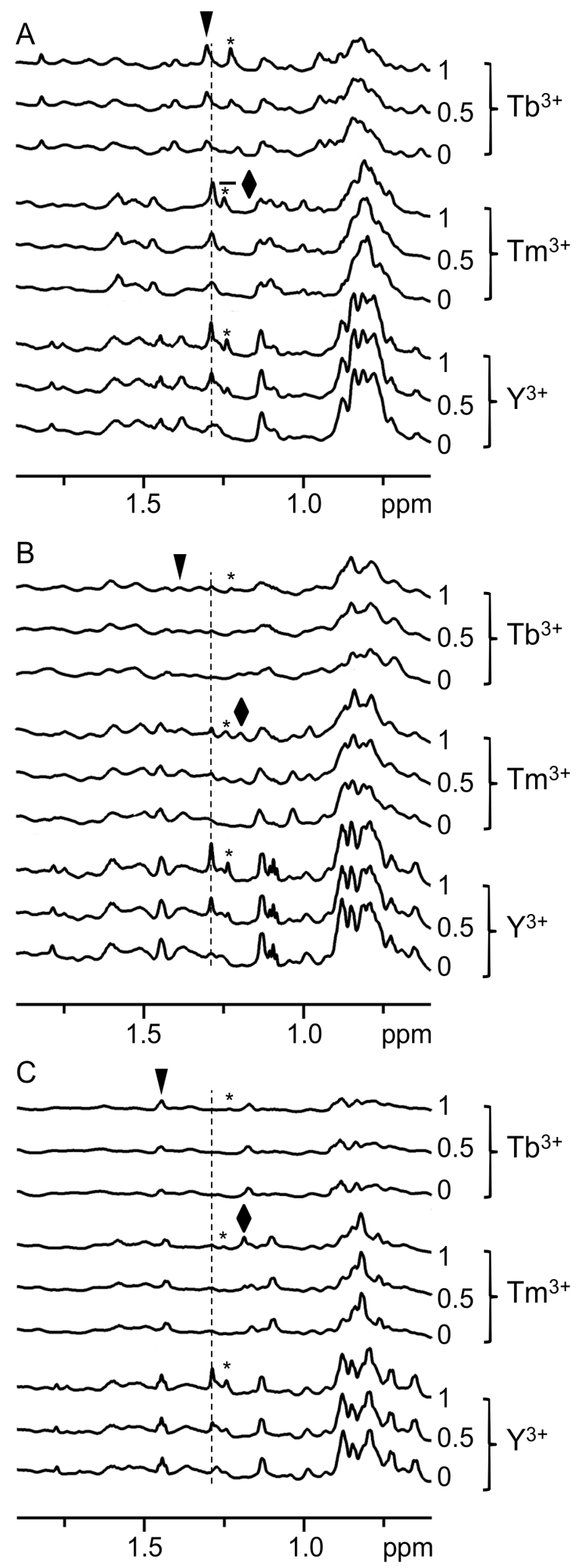

Figure S5. PCSs of the tert-butyl signal observed in $1 \mathrm{D}^{1} \mathrm{H}$ NMR spectra measured of ligand $\mathbf{1}$ in complex with DENpro with different $\mathrm{C} 2-\mathrm{Ln}^{3+}$ tags loaded with different metal ions as indicated. 
The panels A-C show the data obtained with $\mathrm{C} 2-\mathrm{Ln}^{3+}$ tags at sites $\mathrm{A}, \mathrm{B}$, and $\mathrm{C}$, respectively. The spectra were recorded of ca. $150 \mu \mathrm{M}$ solutions of uniformly ${ }^{15} \mathrm{~N}$ labeled DENpro samples in NMR buffer containing $10 \% \mathrm{D}_{2} \mathrm{O}$ at $25{ }^{\circ} \mathrm{C}$. Each panel contains three groups of three spectra, where each group shows the result of titration of the tagged protein with increasing amounts of ligand 1 from bottom to top in stoichiometric ratios as indicated. The dashed line identifies the chemical shift of the tert-butyl signal of the bound ligand in the diamagnetic samples. This chemical shift is independent of the site of the diamagnetic tag and the same as in wild-type protein. Signals from a non-binding impurity in the ligand stock are labeled with a star. Filled rhombuses and triangles mark the chemical shifts of the tert-butyl group in samples tagged with $\mathrm{C} 2-\mathrm{Tm}^{3+}$ and $\mathrm{C} 2-\mathrm{Tb}^{3+}$, respectively. Note the increase of the tert-butyl resonance of bound ligand 1 with increasing ligand concentrations, but also that the tert-butyl resonance is difficult to assign in panels $A$ and $B$ due to spectral changes induced in the protein NMR spectrum upon ligand binding as well as PREs associated with paramagnetic metal ions. 

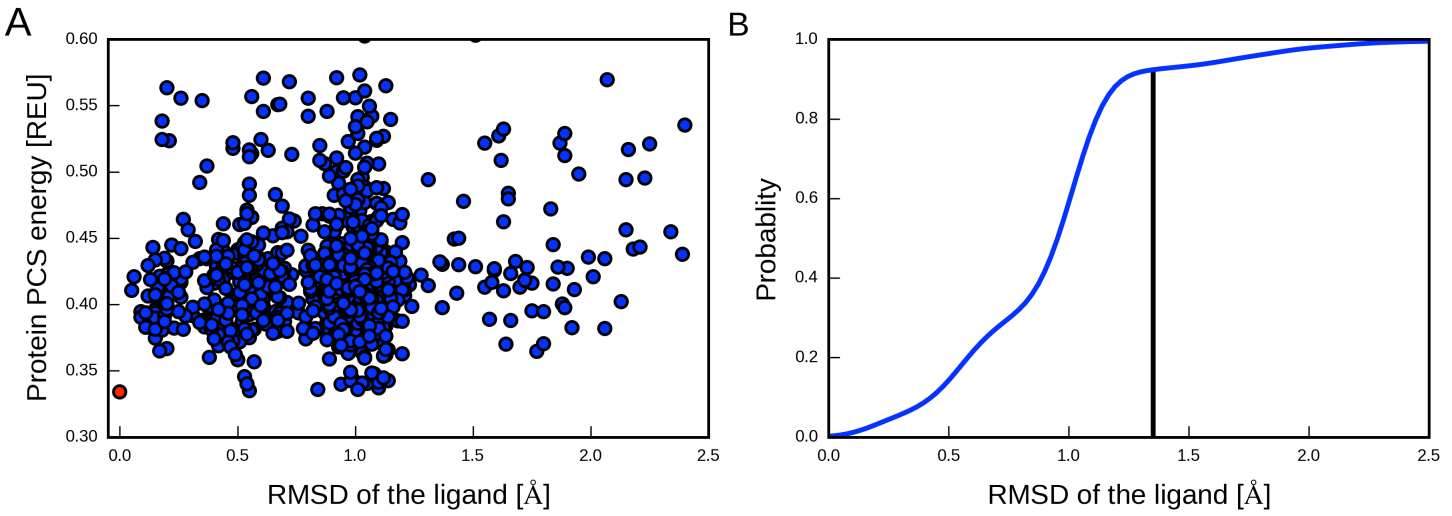

Figure S6. PCS energies and RMSDs of the ligand poses after all-atom Rosetta refinement. (A) PCS energy of the protein (in Rosetta energy units) vs RMSD of the ligand to the final pose (highlighted in red). 1000 structures were produced by the Rosetta refinement protocol, which were all very similar and showed very similar PCS energies. The final ligand pose and protein structure was chosen as the protein-ligand complex with the lowest PCS energy of the protein. The RMSD was calculated for heavy atoms of the ligand only. All ligand poses were within 2.5 $\AA$ from the best pose. (B) Probability density plot of the ligand RMSDs with respect to the final docked pose of the ligand. The vertical bar shows that about $92 \%$ of the ligand poses are within $1.3 \AA$ from the best pose.
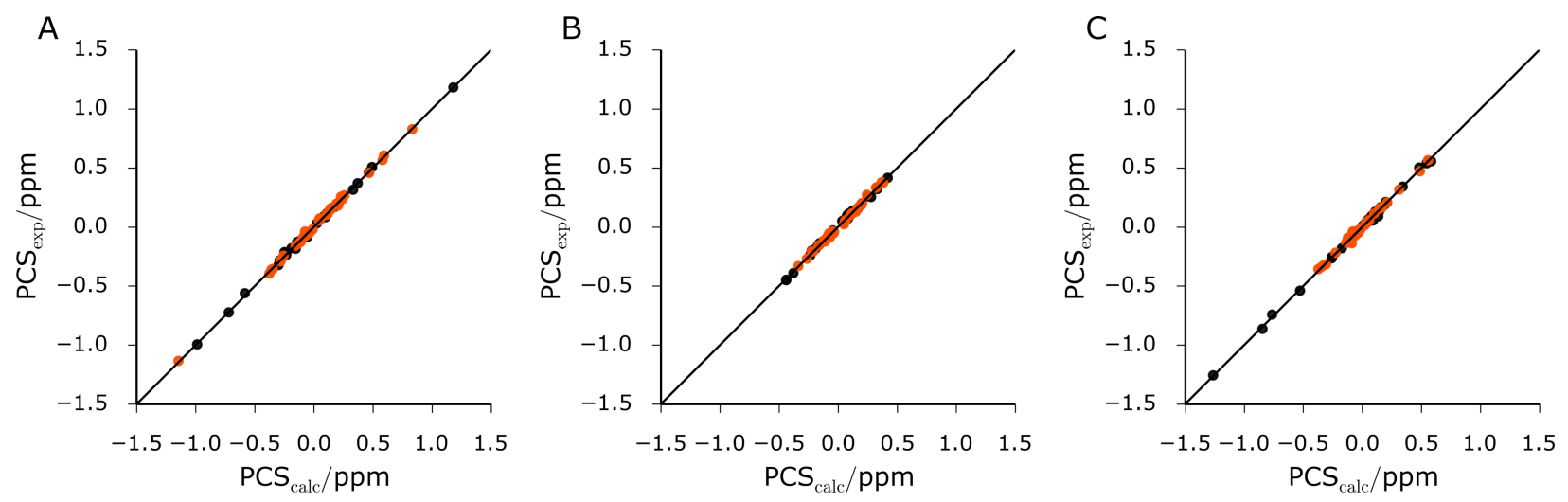

Figure S7. Correlation between experimental and back-calculated PCSs fitted on the model structure. The data from $\mathrm{C} 2-\mathrm{Tm}^{3+}$ and $\mathrm{C} 2-\mathrm{Tb}^{3+}$ tags are shown as red and black points, respectively. (A)-(C) are the correlation plots drawn for the three different mutants A, B, and C, respectively. The $\Delta \chi$ tensor parameters are reported in Table S3. 


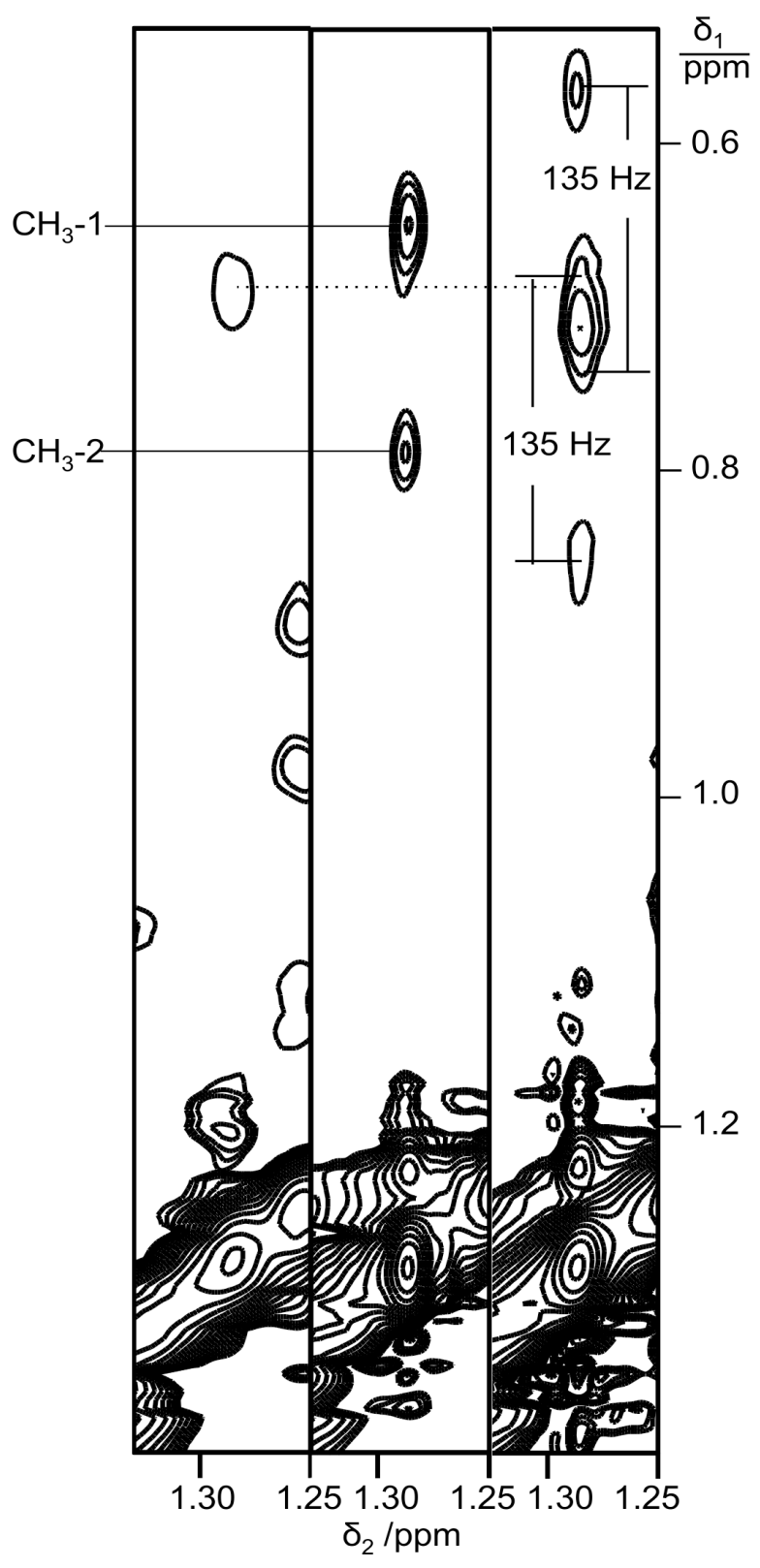

Figure S8. Selected spectral region of NOESY spectra of DENpro in complex with ligand 1, showing cross-peaks between the methyl groups of Val and the tert-butyl resonance of the ligand. The left-most panel shows the spectrum recorded with ligand $\mathbf{2}$, which is devoid of a tertbutyl group. The center and right panels show the spectra of complexes of ligand 1 with unlabeled DENpro and DENpro prepared with ${ }^{13} \mathrm{C} /{ }^{15} \mathrm{~N}$-labeled valine, respectively. The crosspeaks are clearly split by ${ }^{1} J_{\mathrm{CH}}$ couplings in the spectrum with isotope-labeled valine. The chemical shifts of the cross-peaks in the indirect dimensions identify the cross-peaks as NOEs with methyl groups of valine. 


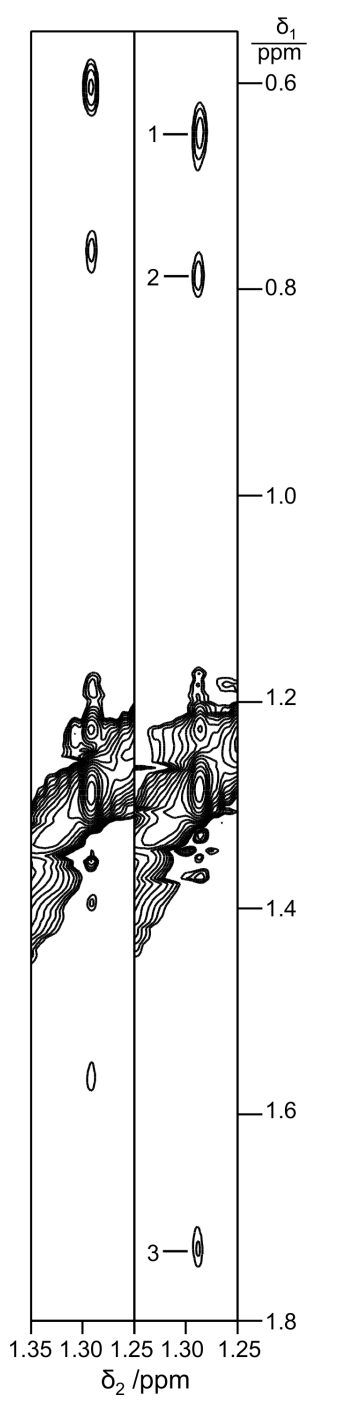

Figure S9. Assignment of NOEs between methyl groups of protein side chains and the tert-butyl group of ligand 1. Right panel: zoom into the spectral region from the NOESY spectrum shown in Figure $2 \mathrm{~B}$ of the main text. Cross-peaks with the tert-butyl resonance of ligand $\mathbf{1}$ are numbered as in Figure 2B. Left panel: same as the right panel, except for the complex of ligand $\mathbf{1}$ with the mutant Val155Ile of DENpro rather than wild-type DENpro. Note that the cross-peaks of the Val155Ile mutant display no splitting by ${ }^{1} J_{\mathrm{HC}}$ couplings, although the protein had been prepared with ${ }^{13} \mathrm{C}$-labeled valine and the spectrum was recorded without ${ }^{13} \mathrm{C}$-decoupling. This result indicates that the cross-peaks 1-3 in wild-type DENpro are with Val155 rather than Val154, and that the corresponding cross-peaks observed in the Val155Ile mutant are with isoleucine. The localization space of the tert-butyl group shown in Figure 4 of the main text is not near any other methyl group of DENpro. Also note that all NOESY cross-peaks with the tertbutyl group are slightly shifted because of a small change in its chemical shift, providing an independent means of identification beyond their narrow line width in the detection dimension. 

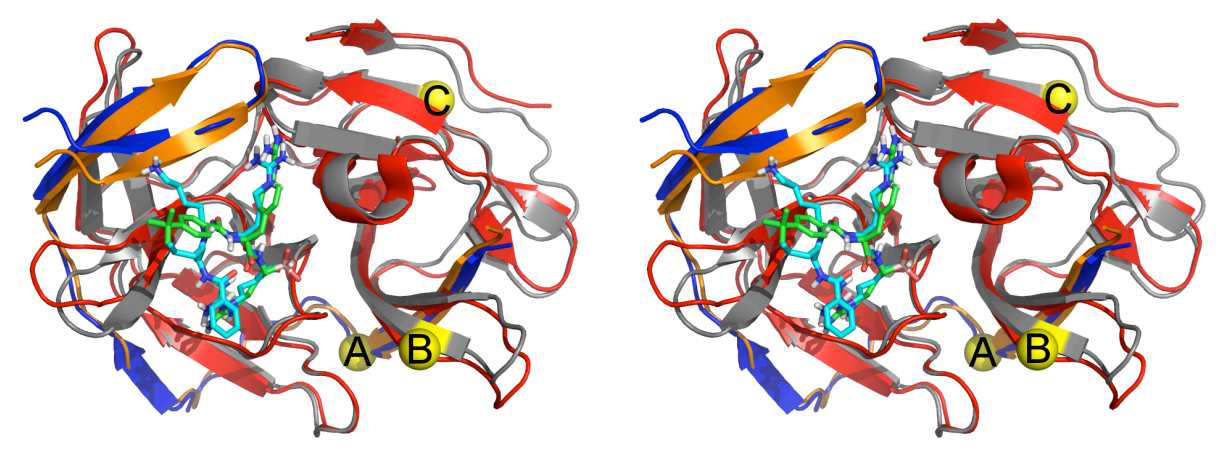

Figure S10. Stereo view comparing the crystal structure of serotype 3 with peptide inhibitor (PDB code 3U1I), ${ }^{3}$ and the Rosetta-refined model structure of DENpro in complex with ligand 1 determined in the present work. The Rosetta all-atom refinement adjusted the conformation of the backbone atoms around the ligand binding site both for NS2B and NS3pro. NS2B and NS3pro of the crystal structure are shown in blue and red, respectively, with the peptide ligand shown in a stick representation with a cyan backbone. NS2B and NS3pro of the model are shown in orange and grey, with ligand $\mathbf{1}$ in a stick representation with green backbone atoms. Nitrogen and oxygen atoms are shown in dark blue and red, respectively. Yellow balls mark the sites A-C mutated to cysteine for attachment of $\mathrm{C} 2-\mathrm{Ln}^{3+}$ tags. The backbone of ligand 1 closely aligns with the backbone of the peptide ligand in the crystal structure. The Rosetta all-atom refinement resulted in a small shift of the C-terminal two-stranded $\beta$-sheet of NS3pro (residues 154-164) and of the C-terminal $\beta$-strand of NS2B (residues $73 *-83 *$ ) towards the ligand.

\section{References}

(1) Schmitz, C.; Stanton-Cook, M. J.; Su, X.-C.; Otting, G.; Huber, T. J. Biomol. NMR 2008, 41, 179-189.

(2) Graham, B.; Loh, C. T.; Swarbrick, J. D.; Ung, P.; Shin, J.; Yagi, H.; Jia, X.; Chhabra, S.; Barlow, N.; Pintacuda, G.; Huber, T.; Otting, G. Bioconjugate Chem. 2011, 22, $2118-$ 2125 .

(3) Noble, C. G.; Seh, C. C.; Chao, A. T.; Shi, P. Y. J. Virol. 2012, 86, 438-446. 